
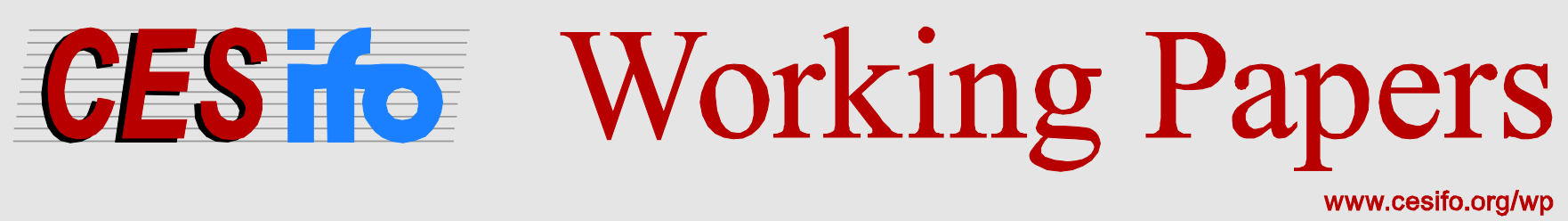

\title{
Normative Analysis with Societal Constraints
}

\author{
Robin W. Boadway \\ Nicolas-Guillaume Martineau
}

CESIFO WORKING PAPER NO. 4305

CATEGORY 1: Public FinANCE

JUNE 2013

An electronic version of the paper may be downloaded

- from the SSRN website:

- from the RePEc website:

- from the CESifo website:

WWW.SSRN.com

www.RePEc.org

www.CESifo-group.org/wp

\section{CESifo}




\title{
Normative Analysis with Societal Constraints
}

\begin{abstract}
This paper examines the question of achieving a societal consensus around redistributive policies. Its extent is measured by the degree of work participation among the different skill classes that populate the economy. This consensus is driven both by the material incentives and heterogeneous preferences for leisure of each skill class, and an endogenous social norm, which embodies societal attitudes towards distributive justice. Results for optimal redistributive taxation in the presence of an extensive margin of participation show that when a norm is present, participation taxes are generally lower (resp. higher) than when it is not, whenever it enters as a benefit or cost for participants (resp. a cost for non-participants). In the event of multiple participation equilibria, it is examined how changes in the progressivity of taxation may induce shifts in equilibria. This multiplicity of equilibria is thereafter exploited as a constraint on the social planner, which views societal consensus as an objective.
\end{abstract}

JEL-Code: D630, H210.

Keywords: optimal taxation, societal consensus, social norms, work participation, distributive justice, redistribution.

\author{
Robin W. Boadway \\ Department of Economics \\ Queen's University \\ Dunning Hall, 94 University Avenue \\ Canada - Kingston ON K7L 3N6 \\ boadwayr@econ.queensu.ca
}

\author{
Nicolas-Guillaume Martineau \\ Department of Economics \\ University of Sherbrooke \\ 2500, Boulevard de l'Université \\ Canada - Sherbrooke QC J1K 2R1 \\ nicolas-guillaume. \\ martineau@usherbrooke.ca
}

June 2013

We wish to thank Al Slivinsky for commenting on an earlier version of this paper. We also wish to thank Laurence Jacquet at CESifo Public Sector Meetings 2013, seminar participants at UQAM, as well as Jean-Guillaume Forand, and various other participants at CPEG 2012 Concordia University, all for helpful comments. 


\section{Introduction}

This paper seeks to investigate the importance of achieving a societal consensus surrounding questions of redistribution. This societal consensus is measured by the extent of co-operative behaviour in work participation decisions, and rests on social norms which induce work participation above or below what would result from pure self-interested behaviour. This paper precisely asks what the presence of such social norms concerning work participation entails for (optimal) redistributive income taxation, how a social planner's problem should be conditioned on the prevailing degree of societal cohesion, and how it can in turn be altered.

It is shown here that the extent of the prevalent societal consensus (i.e., whether the economy is characterized by a low or a high work participation in equilibrium) matters for a social planner's choice of redistributive taxes, its general effect being to constrain the optimal participation tax rates. Reciprocally, this societal consensus can be fostered or hindered by the social planner's choices of redistributive income tax schedules. In that spirit, an engineered shift from a low- to a high-participation equilibrium (i.e., increasing societal cohesion) can be Pareto-improving, but may run counter to the social planner's aversion to inequality and consequent redistributive choices.

Motivating this enquiry is the importance for normative analysis of the social planner's choice of objective function and the constraints to which it is subjected. These need to satisfy some basic characteristics so as to be representative of the individuals' preferences, and so as to give adequate policy advice. Some characteristics of social welfare functions are innocuous and commonly assumed, for instance individualism (basing utilities on individuals' true preferences), anonymity (treating individuals alike) and the Pareto principle. Yet appropriate policy choices require much more, especially with regard to questions of redistributive taxation, where interpersonal comparisons of utility and their aggregation across individuals particularly matter. Such value judgements then need to conform with the prevailing social consensus, shaped by the social norms and the redistributive policies already in place. This societal consensus thus acts as a constraint on the social planner's (or party in power's) choice of policies, but is not immutable for it can in turn be altered by the implementation of certain policies and through other forms of social engineering.

Underpinning this paper's definition of societal consensus is co-operative behaviour, which is fostered or discouraged by a social norm that influences work participation decisions, and that embodies prevailing societal views of redistributive justice. Seminal work on social norms by Akerlof (1980) examined how they may drive the wage-setting process, leading to a "fair" wage being chosen (rather than a market-clearing wage) and involuntary unemployment. Social norms have been shown to explain deviations from purely rational and self-interested behaviour, for instance in the context of tax evasion (Gordon, 1989; Myles and Naylor, 1996), and to reconcile theoretical results with conflicting empirical evidence. They have also recently been shown (Cervellati, Esteban and Kranich, 2010) to matter in the context of the intensity of labour supply. They can then serve to explain certain politico-economic attitudes towards redistribution that standard models (e.g., Romer, 1975; Meltzer and Richard, 1981) cannot: for instance, how economies with similar initial income distributions and social preferences may still differ in their chosen levels of redistribution 
and their degree of social cohesion, as measured by the individuals' compliance with the work hours norm. Such norms concerning the intensity of labour supply were also applied to the context of optimal income taxation by Aronsson and Sjögren (2010).

In more closely-related work, other authors have invoked social norms to explain the compounding of moral hazard effects caused by the welfare state's social programs over the long run (Lindbeck, 1995, Lindbeck, Nyberg and Weibull, 1999 , Dufwenberg and Lundholm, 2001; Lindbeck, Nyberg and Weibull, 2003). This analysis was done in the context of a reconsideration of the scope and organization of the welfare state in Europe, following persistently low levels of work participation, and correspondingly-high levels of benefit claims. This state of affairs was deemed to result from a weakening of norms - either favouring societal co-operation through moral benefits of participation, or deterring non-participation through the stigma of receiving social assistance benefits - which followed strong adverse macroeconomic shocks having thrown many individuals onto social safety nets for prolonged periods of time. The present paper differs from previous approaches by examining the desirability of, and possibility for, societal cohesion and how it interacts a social planner's (or party in office's) social objectives. This analysis is both positive and normative, and makes use of a broad range of income tax instruments, whereas the work of Lindbeck, Nyberg and Weibull 1999, 2003), for instance, is chiefly characterized by a positive analysis of welfare-state dynamics through median-voter processes and a linear income tax.

This paper's norms affecting work participation decisions are also modelled so as to embody prevailing societal views of distributive justice. These can take two conflicting forms, based upon seminal works of philosophy (e.g., Rawls, 1971, Nozick, 1974) and found in the recent literature (e.g., Bénabou and Tirole, 2006): either economic outcomes are viewed to be the result of sheer luck (which justifies redistribution as a means of compensating the worse-off), or are attributed to effort only (in which case the laissez-faire is optimal). This leads to the derivation of generalized marginal social welfare weights to the planner's problem that reflect such views, without them being embodied in the social welfare function, thus linking this paper to the recent work of Saez and Stantcheva (2013).

This analysis conducted in the course of this paper yields the following results. First, it is found that the social norm, when included as an incitement or a deterrent to co-operation affecting participants, will reduce the optimal participation tax rates relative to the case where it is absent. Our paper's model of optimal income taxes and work participation decisions where there is no social norm corresponds to Saez (2002) (based on the contribution of Diamond, 1980). This result is attributable to how a change in the tax incentives to participate is compounded by the presence of the social norm, which makes participation more volatile - thus amplifying the budgetary loss of increasing redistribution to non-participants, while also calling for less of it, for lower numbers of non-participants increase the welfare of participants. This does not however necessarily hold when the social norm enters as a cost for non-participants. A higher participation tax may result than in the case without a social norm if the planner sufficiently cares about the welfare of non-participants, and the feedback effects of the social norm on participation and budgetary balance are relatively 
mild.

It is also investigated how the social norm can lead to the existence of multiple locally-stable equilibria in work participation. Transitions between high- and low-participation equilibria can be induced by changes in the income tax schedule. Conditions for the Pareto-dominance of a highparticipation equilibrium over its low-participation counterpart are also derived, and are shown to constrain the choices of a social planner engineering a transition from the latter to the former equilibrium, by reducing the prevailing extent of redistribution compared with (unconstrained) optimal tax problem.

The paper is organized as follows. Section 2 first defines individual preferences, the nature of the social norm, and how they jointly determine individual work participation decisions. It also examines how the social norm may lead to a single equilibrium or multiple locally-stable equilibria in work participation. Section 3 then considers the optimal redistribution problem of a "naïve" or myopic social planner, that is one not explicitly considering the potential multiplicity in equilibria when solving for the optimal tax structure. The next section (Section 4 ) generally considers the issue of the incentives provided by the welfare state through a redistributive income tax, their interaction with a social norm concerning work participation, and how they may lead to different levels of societal co-operation and equilibria in work participation. It finally considers the question of transitions from low- to high-participation equilibria, and how socially engineering them through material incentives may conflict with the social planner's objective. Finally, Section 5 concludes this paper with a summary and a discussion of its results.

\section{Labour market participation, social norms, and optimal redis- tribution}

We consider how social norms concerning work-force participation interact with the implementation of a certain redistributive taxation schedule. In effect, the compliance of the population with the endogenous social norm determines the extent of redistribution possible, and the potential need for taxation policy to trigger a shift in participation. To study this issue transparently, we adopt the pure extensive labour supply model of Diamond (1980) and Saez (2002). It is augmented with a social norm, either in the form of an inducement or deterrent to participate, which respectively mitigates or amplifies the extent to which a productive individual may choose to remain idle instead of working, out of self-interested behaviour.

Let there be a population, normalized to be of size 1, composed of $I+1$ skill classes denoted by $i=0,1 \ldots, I$, each of natural population $n_{i}$ (that is to say, the population endowed with a certain skill set). Contrast this with the effective population of each class, denoted by $h_{i}$, which results from the work participation decisions of its individual members. With each of these skill classes is associated an exogenous income $w_{i}$, identical for all working members of a given skill, and preferences for leisure that are heterogeneous both within a skill class and between classes. The participation decision of an individual in any given class but class 0 (who is deemed to be 
inactive) therefore hinges jointly on preferences for leisure and the social norm, both of which will be explicitly described later. The number of non-participants, $h_{0}=1-\sum_{i \neq 0} h_{i}$, includes persons of all skill levels who choose not to participate.

The next subsections are as follows. First, the participation decision, and how the social norm enters it are explained at length. Second, the impact of the social norm on the work participation elasticity of each skill group is considered. Third, we investigate the existence and stability conditions for there to be an equilibrium (or many equilibria) in participation for a given tax schedule, a distribution of preferences for leisure, and the norm. Finally, the social planning problem for a redistributive taxation schedule is solved, and the results are compared with the canonical Saez (2002) optimal taxation formula in the presence of an extensive margin of participation only.

\subsection{The participation decision: preferences for leisure and the social norm}

We first describe the participation decision, which will be useful for characterizing the optimal tax problem, and in so doing we specify functional forms for utility and the social norm.

\subsubsection{Characterizing preferences}

Assume a certain distribution of leisure preferences in each skill class $i$, with utility being quasilinear in consumption so as to abstract from income effects. Let $v_{i}$ be the utility of leisure for a person with skill level $i$, where $v_{i}$ is stochastic and follows the distribution $\Gamma_{i}\left(v_{i}\right)$. An individual in class $i$ with utility of leisure $v_{i}$ will participate in the labour force if:

$$
c_{i}+x\left(h_{0}, c_{0}\right) \geq c_{0}+v_{i}
$$

where $x\left(h_{0}, c_{0}\right)$ is the co-operative incitement (or deterrent) to participate, which depends on the total number of non-participants of all types ${ }^{1}$ and the level of transfers accruing to them. The function $x(\cdot, \cdot)$ is assumed to be the same for all individuals and to embody a certain societal view of distributive justice, which affects one's moral inclination to participate in the work force. We consider two diametrically opposed cases: the first, where economic outcomes are attributed to luck; and the second, when they are attributed to effort.

\footnotetext{
${ }^{1}$ The function's argument is here the number of non-participating individuals, but it could very well be re-written as a function of participating individuals: $x\left(1-\sum_{i \neq 0} h_{i}, c_{0}\right)$, where as mentioned $h_{i}$ is the effective population of skill class $i$.
} 
The social norm when economic outcomes are attributed to luck In the case of economic outcomes being attributed to luck, the function $x(\cdot, \cdot)$ has the following properties:

$$
\begin{aligned}
x\left(h_{0}, c_{0}\right) \geq & 0 \forall\left(h_{0}, c_{0}\right) \\
x_{h} \equiv & \frac{\partial x}{\partial h_{0}}<0 \\
x_{c} \equiv & \frac{\partial x}{\partial c_{0}}>0 \forall c_{0}<\bar{c}_{0} \\
& <0 \text { otherwise } \\
x_{c h} \equiv & \frac{\partial^{2} x}{\partial h_{0} \partial c_{0}}>0 \forall c_{0}<\bar{c}_{0} \\
& <0 \text { otherwise. }
\end{aligned}
$$

A positive moral benefit (i.e., a co-operative incitement to participate) could thus only be present for a certain range of $h_{0} \in\left[0, \bar{h}_{0}\right]$, where for all $h_{0}>\bar{h}_{0}, x\left(h_{0}, c_{0}\right)=0$, and purely self-interested behaviour once again prevails. The final cross-partial derivative (for which Young's theorem holds, the function $x$ being continuous) states that non-participation and transfers to the idle are complements, for all $c_{0}<\bar{c}_{0}$, where $\bar{c}_{0}$ is some threshold level of transfers to the idle. An increase in the transfers to non-participants translates into an increase in the marginal moral benefit (or, more accurately, a decrease in the marginal moral cost) of seeing more members of class 0. Reciprocally, for a given level of transfers, an increase in $h_{0}$ increases the marginal moral benefit of redistributing to the idle.

The moral benefits accruing to participants are positive and increasing in $c_{0}$, and non-participation and transfers are complements? jointly, this evokes the view that non-participants are not responsible for their fate. Meanwhile, the function $x(\cdot, \cdot)$ reflects the fact that the norm morally rewards conformism: the moral benefits of participation are decreasing in the number of non-participants. Yet they decrease at a slower rate when $c_{0}$ increases, due the moral benefit of not stigmatizing non-participants for their fate, and redistributing income towards them.

\footnotetext{
${ }^{2}$ Note however that whenever transfers are above some threshold $\bar{c}_{0}$, the complementarity relationship then becomes one of substitutability: increasing transfers to the idle decreases the marginal moral benefit (increases the marginal moral cost) of seeing more members of class 0 , while increasing $h_{0}$ further decreases the moral benefit of redistributing to the idle.
} 
The social norm when economic outcomes are attributed to effort In the case of economic outcomes being attributed to effort, the function $x(\cdot, \cdot)$ takes the following form:

$$
\begin{aligned}
x\left(h_{0}, c_{0}\right) & =0 \text { for } c_{0}=0 \text { or } h_{0}=0 \\
& <0 \text { otherwise } \\
x_{h} & \equiv \frac{\partial x}{\partial h_{0}}<0 \\
x_{c} & \equiv \frac{\partial x}{\partial c_{0}}<0 \forall c_{0} \\
x_{c h} & \equiv \frac{\partial^{2} x}{\partial h_{0} \partial c_{0}}<0 \forall c_{0} .
\end{aligned}
$$

Note here that the function takes non-positive values, rather than non-negative ones. It therefore acts as a moral cost of participation, or a "co-operative" deterrent to participate: the sight of idleness, attributed to a lack of effort, weakens the resolve of participants to work and fund transfers to nonparticipants. Its effect is therefore to lower participation below the self-interest benchmark. Also noteworthy is the complementarity ${ }^{3}$ between idleness and the level of transfers, which signifies that for participants, the marginal moral cost of idleness $\left(x_{h}\right)$ increases as transfers $\left(c_{0}\right)$ increase, and that the marginal moral cost of transfers to the idle increases the more non-participants there are.

Another, starker way of modelling economic outcomes being attributed to effort is for the moral cost to affect non-participants instead: this reflects the stigma incurred by those who do not work, as a result of societal attitudes towards idleness. In such a case, the utility of participants in class $i$ would be $c_{i}+v_{i}$, and that of non-participants from class $i, c_{0}+v_{i}+x\left(h_{0}, c_{0}\right)$. The function $x(\cdot, \cdot)$ then has the same properties as stated in (2) (including $x_{c}<0$ : the stigma increases as $c_{0}$ does), except that now $x_{h}>0$ (more non-participants decreases stigma, and makes $x(\cdot, \cdot)$ less negative; however, increasing $c_{0}$ decreases the positive marginal effect of an increase in $h_{0}$ on stigma, hence it is still that $x_{c h}<0$ ), but its effect is to increase participation above self-interested levels, as in the case of outcomes being attributed to luck. (Note that there does not exist an analogous way of modelling the norm as a moral cost to non-participants when outcomes are attributed to luck, as there should then be no such stigma befalling them.)

In what follows, we chiefly focus on the norm affecting participants, but still allow for a norm affecting non-participants wherever it leads to different results.

Effective skill class populations The cut-off individual in each skill class $i$ is the person who is indifferent between working and being idle. Let $\hat{v}_{i}$ be his preference for leisure, which satisfies:

$$
\begin{aligned}
c_{i}+x\left(h_{0}, c_{0}\right) & =c_{0}+\hat{v}_{i} \\
\Longleftrightarrow \hat{v}_{i} & =c_{i}-c_{0}+x\left(h_{0}, c_{0}\right)
\end{aligned}
$$

\footnotetext{
${ }^{3}$ The negative cross partial derivative $x_{c h}$ here represents complementarity, due to the function and both partial derivatives $x_{h}$ and $x_{c}$ taking negative values: an increase in transfers to non-participants increases the marginal moral cost caused by their numbers (i.e., makes $x_{h}$ more negative), while an increase in their numbers increases the marginal moral cost caused by transfers (i.e., makes $x_{c}$ more negative).
} 
regardless of how the norm is modelled, as long as it affects participants 4 Thus, if the natural population of each skill class is given by $n_{i}$, with $\sum_{i=0}^{I} n_{i}=1$, then $h_{i}$, the effective population of class $i$, is then:

$$
\begin{aligned}
h_{i}\left(c_{i}-c_{0}+x\left(h_{0}, c_{0}\right)\right) & =n_{i} \Gamma_{i}\left(c_{i}-c_{0}+x\left(h_{0}, c_{0}\right)\right) \forall i>0 \\
h_{0} & =n_{0}+\sum_{i \neq 0} n_{i}\left(1-\Gamma_{i}\left(c_{i}-c_{0}+x\left(h_{0}, c_{0}\right)\right)\right) \\
& =1-\sum_{i \neq 0} n_{i} \Gamma_{i}\left(c_{i}-c_{0}+x\left(h_{0}, c_{0}\right)\right)
\end{aligned}
$$

Having fully characterized the participation decisions of each class and the preferences underlying it, let us turn to how the social norm impacts the elasticity of participation of each skill class.

\subsection{The impact of a social norm on the elasticity of participation}

In the absence of a social norm determining the extent of societal co-operation, the number of participants of skill class $i$ can be represented by: $h_{i}\left(c_{i}-c_{0}\right)$, with $h_{i}^{\prime}\left(c_{i}-c_{0}\right)>0, h_{i}>0 \forall c_{i}-c_{0}>$ 0 , and $h_{i}=0 \forall c_{i}-c_{0} \leq 0$.

In keeping with the previous subsection, let us augment this by making participation a function of $h_{0}$, the inactive portion of the population, so that the number of type- $i$ participants is $h_{i}\left(c_{i}-\right.$ $\left.c_{0}+x\left(h_{0}, c_{0}\right)\right)$, where:

$$
\frac{\partial h_{i}}{\partial h_{0}}=h_{i}^{\prime}\left(c_{i}-c_{0}+x\left(h_{0}, c_{0}\right)\right) x_{h}<0 \forall i \neq 0
$$

Since total population is normalized to be 1 , that means in turn:

$$
h_{0}=1-h_{i}\left(c_{i}-c_{0}+x\left(h_{0}, c_{0}\right)\right)-\sum_{j \neq 0, i} h_{j}\left(c_{j}-c_{0}+x\left(h_{0}, c_{0}\right)\right)
$$

which implies:

$$
\frac{\mathrm{d} h_{0}}{\mathrm{~d} h_{0}}=\frac{\partial h_{0}}{\partial h_{0}}=-\sum_{i \neq 0} h_{i}^{\prime}\left(c_{i}-c_{0}+x\left(h_{0}, c_{0}\right)\right) x_{h}
$$

and:

$$
\frac{\partial^{2} h_{0}}{\partial h_{0}^{2}}=-\left(\sum_{i \neq 0} h_{i}^{\prime \prime}\left(c_{i}-c_{0}+x\left(h_{0}, c_{0}\right)\right) x_{h}+\sum_{i \neq 0} h_{i}^{\prime}\left(c_{i}-c_{0}+x\left(h_{0}, c_{0}\right)\right) x_{h h}\right) .
$$

${ }^{4}$ If it affects non-participants, we have instead:

$$
c_{i}=c_{0}+\hat{v}_{i}+x\left(h_{0}, c_{0}\right)
$$

and thus:

$$
\begin{aligned}
h_{i}\left(c_{i}-c_{0}-x\left(h_{0}, c_{0}\right)\right) & =n_{i} \Gamma_{i}\left(c_{i}-c_{0}-x\left(h_{0}, c_{0}\right)\right) \forall i>0 \\
h_{0} & =n_{0}+\sum_{i \neq 0} n_{i}\left(1-\Gamma_{i}\left(c_{i}-c_{0}-x\left(h_{0}, c_{0}\right)\right)\right) .
\end{aligned}
$$


The elasticity of participation in the absence of a norm is generally defined thus:

$$
\eta_{i} \equiv \frac{c_{i}-c_{0}}{h_{i}} \frac{\mathrm{d} h_{i}}{\mathrm{~d}\left(c_{i}-c_{0}\right)}=\frac{c_{i}-c_{0}}{h_{i}\left(c_{i}-c_{0}\right)} h_{i}^{\prime}\left(c_{i}-c_{0}\right)
$$

which depends only on $c_{i}-c_{0}$.

Yet in the presence of a social norm, the elasticity of participation depends not only on the direct reward from participating $c_{i}-c_{0}$, but also on the total number of non-participants $h_{0}$, and the absolute level of $c_{0}$. The total effect of a change in $c_{i}-c_{0}$ feeds back into $h_{0}$, first by the direct effect of a change in the participation of group $i$, and second, by a change in the participation of all other groups, which in turns affects $h_{0}$, etc. The system's stability is by no means guaranteed: following a small disturbance, it could spiral up to (near) full participation for all members of all groups except of those of skill 0 , or down to minimal participation.

Putting these concerns aside for the moment (the next subsection considers them at length), the new elasticity measure can be written:

$$
\xi_{i}=\frac{c_{i}-c_{0}}{h_{i}} \frac{\mathrm{d} h_{i}}{\mathrm{~d}\left(c_{i}-c_{0}\right)}=\frac{c_{i}-c_{0}}{h_{i}}\left(h_{i}^{\prime}+h_{i}^{\prime} x_{h} \frac{\mathrm{d} h_{0}}{\mathrm{~d}\left(c_{i}-c_{0}\right)}\right)
$$

by the chain rule, keeping here $c_{0}$ constant for simplicity ${ }^{5}$ Note that since $h_{0}$ is a function of all $h_{j}$ (including $h_{i}$, which depends on $c_{i}-c_{0}$ ), which are in turn functions of $h_{0}$, it follows from (3) that:

$$
\begin{aligned}
\frac{\mathrm{d} h_{0}}{\mathrm{~d}\left(c_{i}-c_{0}\right)} & =-\frac{\mathrm{d} h_{i}}{\mathrm{~d}\left(c_{i}-c_{0}\right)}-\sum_{j \neq 0, i} h_{j}^{\prime} x_{h} \frac{\mathrm{d} h_{0}}{\mathrm{~d}\left(c_{i}-c_{0}\right)} \\
\Longleftrightarrow \frac{\mathrm{d} h_{0}}{\mathrm{~d}\left(c_{i}-c_{0}\right)} & =-\frac{\mathrm{d} h_{i}}{\mathrm{~d}\left(c_{i}-c_{0}\right)} \frac{1}{1+\sum_{j \neq 0, i} h_{j}^{\prime} x_{h}} \equiv-\frac{\mathrm{d} h_{i}}{\mathrm{~d}\left(c_{i}-c_{0}\right)} \frac{1}{1+A_{i}} .
\end{aligned}
$$

Since an increase in $c_{i}-c_{0}$ should increase $h_{i}$ and decrease $h_{0}$ - thereby making the left-hand side of equation 5 negative, and first term of its right-hand side positive - the second term on the righthand side, $\left(1+A_{i}\right)^{-1}$, must be positive, which implies that $A_{i}=\sum_{j \neq 0, i} h_{j}^{\prime} x_{h}>-1$. Interestingly, (5) can be rewritten as:

$$
\frac{1}{1+A_{i}}=-\frac{\mathrm{d} h_{0}}{\mathrm{~d} h_{i}}
$$

Combining (5) with (4) yields:

$$
\frac{\mathrm{d} h_{i}}{\mathrm{~d}\left(c_{i}-c_{0}\right)}=h_{i}^{\prime}\left(\frac{1+\sum_{j \neq 0, i} h_{j}^{\prime} x_{h}}{1+\sum_{j=1}^{I} h_{j}^{\prime} x_{h}}\right) .
$$

Since $h_{j}^{\prime} x_{h}<0 \forall j \neq 0$ (less participation breeds less participation, either by decreasing the moral benefit or cost of participation, or by lowering the stigma attached to receiving transfers), we have

\footnotetext{
${ }^{5}$ Not doing so would only add an extra term to the above equation, $-\left(\left(c_{i}-c_{0}\right) / h_{i}\right)\left(h_{i}^{\prime} x_{c} \mathrm{~d} h_{0} / \mathrm{d}\left(c_{i}-c_{0}\right)\right)$, without changing the overall characteristics of the newly-found elasticity function.
} 
that:

$$
\frac{1+\sum_{j \neq 0, i} h_{j}^{\prime} x_{h}}{1+\sum_{j=1}^{I} h_{j}^{\prime} x_{h}}>1 \text { so } \quad \frac{\mathrm{d} h_{i}}{\mathrm{~d}\left(c_{i}-c_{0}\right)}>h_{i}^{\prime}=\frac{\partial h_{i}}{\partial\left(c_{i}-c_{0}\right)} .
$$

Participation is thus more responsive following infinitesimal changes in consumption bundles with the addition of the social norm than without, where the total derivative would then be equal to the partial derivative. This is expected, due to feedback effects on participation.

What about the elasticity of participation, then? When outcomes are attributed to luck, or when the norm enters as a moral cost for non-participants, it increases each group's participation relative to the self-interest benchmark. Yet, by the argument outlined above in mathematical terms, it also increases the responsiveness of each group's participation following changes in relative consumption bundles. Comparing elasticities of participation therefore leads to ambiguous results, since for a given tax-and-transfer scheme denoted by $c_{i}-c_{0} \forall i \neq 0$, and for $x\left(h_{0}, c_{0}\right)>0$ :

$$
h_{i}\left(c_{i}-c_{0}+x\left(h_{0}, c_{0}\right)\right)>h_{i}\left(c_{i}-c_{0}\right)
$$

while, by virtue of the above discussion, it was shown that:

$$
\frac{\mathrm{d} h_{i}\left(c_{i}-c_{0}+x\left(h_{0}, c_{0}\right)\right)}{\mathrm{d}\left(c_{i}-c_{0}\right)}>\frac{\partial h_{i}\left(c_{i}-c_{0}+x\left(h_{0}, c_{0}\right)\right)}{\partial\left(c_{i}-c_{0}\right)}=\frac{\mathrm{d} h_{i}\left(c_{i}-c_{0}\right)}{\mathrm{d}\left(c_{i}-c_{0}\right)}
$$

which implies:

$$
\xi_{i}=\frac{c_{i}-c_{0}}{h_{i}\left(c_{i}-c_{0}+x\left(h_{0}, c_{0}\right)\right)} \frac{\mathrm{d} h_{i}\left(c_{i}-c_{0}+x\left(h_{0}, c_{0}\right)\right)}{\mathrm{d}\left(c_{i}-c_{0}\right)} \gtrless \frac{c_{i}-c_{0}}{h_{i}\left(c_{i}-c_{0}\right)} \frac{\mathrm{d} h_{i}\left(c_{i}-c_{0}\right)}{\mathrm{d}\left(c_{i}-c_{0}\right)}=\eta_{i} .
$$

The only exception to this occurs when the norm embodies the view that outcomes are attributed to effort, and it enters the utility of participants as a moral cost. Since participation is depressed relative to the self-interest benchmark, it is now that $\xi_{i}>\eta_{i}$.

Let us now turn to the determination of (stable) equilibrium levels of participation induced by the social norm.

\subsection{Equilibrium participation and the social norm}

In this subsection, we consider conditions necessary and sufficient for the social norm to lead to at least one stable equilibrium in participation. Though we characterize them explicitly only for a norm affecting participants, the same conditions hold when it affects non-participants instead.

The equilibrium resulting from the social norm (i.e., $h_{0}$, the number of inactive individuals) is the solution of the following fixed-point equation:

$$
h_{0}=1-\sum_{i \neq 0} h_{i}\left(c_{i}-c_{0}+x\left(h_{0}, c_{0}\right)\right)
$$


This fixed-point equation may have no solutions, a single solution, or multiple solutions, each of which can be locally stable or not. We consider under what conditions such scenarios are foreseeable, and which ones may be particularly interesting for further consideration: namely, the cases where there can be (at least) two locally-stable equilibria, one characterized by low participation (a "bad" or "vicious" equilibrium), and another by high participation (a "good" or "virtuous" equilibrium).

Note first that the right-hand side of the above equation is an increasing function of $h_{0}$, and so is its left-hand side. Consider the case where $h_{0}=n_{0}$, the number of type- 0 persons, so all persons with skills $i>0$ fully participate. It is therefore plain to see that a stable equilibrium will exist provided that the right-hand-side, when evaluated at $n_{0}$, exceeds $n_{0}$, and that its slope is less than 1 . More formally, the above equation represents a generally non-linear, first-order difference equation in $h_{0}$, which can be represented by a phase diagram. Re-write it as follows for added clarity:

$$
h_{0}^{+}=1-\sum_{i \neq 0} h_{i}\left(c_{i}-c_{0}+x\left(h_{0}, c_{0}\right)\right)
$$

where the superscript "+" denotes the temporally subsequent value, when iterating.

This function maps from $A=\left[n_{0}, 1\right]$ to itself. One may here invoke Brouwer's fixed point theorem, since the function $h_{0}=f\left(h_{0}\right)$ is assumed to be continuous (and if it were assumed otherwise, Tarsky's fixed point theorem could still be used). Brouwer's theorem states that for the continuous function to have a fixed point, the set $A$ must be compact, convex and non-empty. That interval of the real line satisfies all three conditions. Therefore, there exists a fixed point (which may, or may not, be unique). It is an interior solution provided that the function cross the 45-degree line, and a corner solution ( $n_{0}$ or 1 ) if it happens to be completely below or above it, respectively.

Local stability of a steady-state equilibrium $h_{0}^{\star}$ requires that:

$$
\begin{gathered}
\left|\frac{\mathrm{d} h_{0}^{+}\left(h_{0}^{\star}\right)}{\mathrm{d} h_{0}}\right|=\left|-\sum_{i \neq 0} h_{i}^{\prime}\left(c_{i}-c_{0}+x\left(h_{0}^{\star}, c_{0}\right)\right) x_{h}\left(h_{0}^{\star}, c_{0}\right)\right|<1 \\
\Longleftrightarrow \quad \sum_{i \neq 0} h_{i}^{\prime}\left(c_{i}-c_{0}+x\left(h_{0}^{\star}, c_{0}\right)\right) x_{h}\left(h_{0}^{\star}, c_{0}\right)>-1
\end{gathered}
$$

since each $h_{i}^{\prime} x_{h}$ is non-positive for the whole range of $h_{0}$. Furthermore, given that $-\sum_{i \neq 0} h_{i}^{\prime} x_{h}>0$, convergence towards a steady state will occur monotonically.

Participation hinges on two parameters: preferences for leisure, and the social norm itself (more precisely, the moral (dis)incentive to participate, captured by $\left.x\left(h_{0}, c_{0}\right)\right)$. The number of participants of skill-type $i, i>0$ is given by $h_{i}=n_{i} \Gamma_{i}\left(c_{i}-c_{0}+x\left(h_{0}, c_{0}\right)\right)$, and the total number of non-participants is $h_{0}=n_{0}+\sum_{i \neq 0} n_{i}\left(1-\Gamma_{i}\left(c_{i}-c_{0}+x\left(h_{0}, c_{0}\right)\right)\right)$. It is therefore the case that:

$$
\frac{\partial h_{i}}{\partial h_{0}}=h_{i}^{\prime}(\cdot) x_{h}\left(h_{0}, c_{0}\right)=n_{i} \Gamma_{i}^{\prime}(\cdot) x_{h}\left(h_{0}, c_{0}\right) \forall i \neq 0
$$


and:

$$
\frac{\partial^{2} h_{i}}{\partial h_{0}^{2}}=h_{i}^{\prime \prime}(\cdot) x_{h}\left(h_{0}, c_{0}\right)+h_{i}^{\prime}(\cdot) x_{h h}\left(h_{0}, c_{0}\right)=n_{i} \Gamma_{i}^{\prime \prime}(\cdot) x_{h}\left(h_{0}, c_{0}\right)+n_{i} \Gamma_{i}^{\prime}(\cdot) x_{h h}\left(h_{0}, c_{0}\right) \forall i \neq 0
$$

The most interesting cases to be considered are those which exhibit multiple equilibria. Some sort of logistic (S-shaped) function for $h_{0}$, for instance, could lead to this happening, as depicted in Figure 1. But how can it arise from the social norm and the distribution of preferences for leisure?

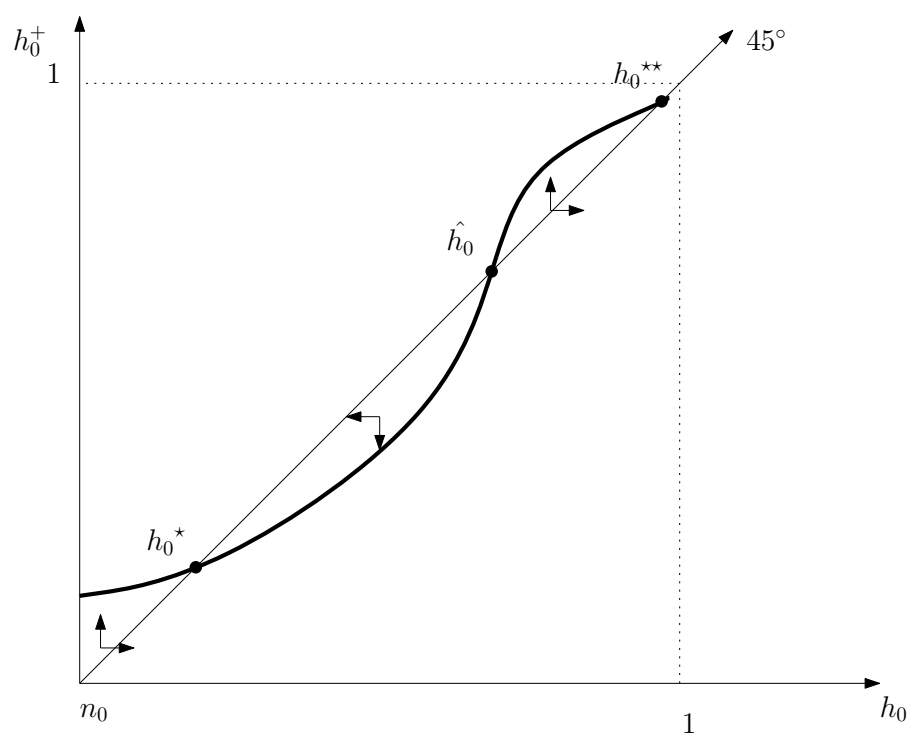

Figure 1: A social norm conducive to multiple, locally-stable participation equilibria.

Let us focus on the characteristics of the social norm by assuming a particular distribution of leisure preferences for each class: namely, that it is uniformly distributed with a certain mean and variance. Denote therefore the probability density function (p.d.f.) for class $i$ as:

$$
\Gamma_{i}^{\prime}\left(v_{i}\right)=\gamma_{i}\left(v_{i}\right)= \begin{cases}\frac{1}{b_{i}-a_{i}} & \forall v_{i} \in\left[a_{i}, b_{i}\right] \\ 0 & \text { otherwise }\end{cases}
$$

It follows that:

$$
\frac{\partial h_{i}}{\partial h_{0}}=h_{i}^{\prime} x_{h}=\frac{n_{i}}{b_{i}-a_{i}} x_{h}\left(h_{0}, c_{0}\right) \forall i \neq 0 \quad \text { and } \quad \frac{\partial^{2} h_{i}}{\partial h_{0}^{2}}=h_{i}^{\prime \prime} x_{h}+h_{i}^{\prime} x_{h h}=\frac{n_{i}}{b_{i}-a_{i}} x_{h h}\left(h_{0}, c_{0}\right) \forall i \neq 0
$$

The slope of equation $h_{0}^{+}=1-\sum_{i \neq 0} h_{i}\left(c_{i}-c_{0}+x\left(h_{0}, c_{0}\right)\right)$ therefore becomes:

$$
\frac{\mathrm{d} h_{0}^{+}}{\mathrm{d} h_{0}}=\sum_{i \neq 0} \frac{n_{i}}{b_{i}-a_{i}} x_{h}\left(h_{0}, c_{0}\right)
$$


while its second derivative is then:

$$
\frac{\mathrm{d}^{2} h_{0}^{+}}{\mathrm{d} h_{0}^{2}}=\sum_{i \neq 0} \frac{n_{i}}{b_{i}-a_{i}} x_{h h}\left(h_{0}, c_{0}\right)
$$

Thus, for this function to have two different segments leading to locally-stable equilibria, the second derivative $x_{h h}$ in equation 9 must change signs. It must therefore be the case that $x\left(h_{0}, c_{0}\right)$ is first decreasing at an increasing rate (its second partial derivative is negative, and the first-difference equation is therefore increasing and convex in $h_{0}$ - both its first and second partial derivatives are positive), then past an inflection point $\hat{h}_{0}, x\left(h_{0}, c_{0}\right)$ is decreasing at a decreasing rate (its second partial derivative is positive, and the first-difference equation is therefore increasing and concave in $h_{0}$ - its second derivative is negative, while its first derivative is positive). For $\hat{h}_{0}$ to be unstable, it must not be a saddle point, which means that $x_{h}\left(\hat{h}_{0}, c_{0}\right)<0$, as is already the case for all other $h_{0} \in\left[n_{0}, 1\right]$.

Having established the conditions necessary and sufficient for a locally-stable equilibrium in labour force participation to exist, let us now turn to the determination of optimal redistributive taxation in the presence of such a social norm.

\section{The basic optimal redistribution problem in the presence of a social norm}

We characterize the optimal redistributive tax-and-transfer scheme in the presence of a social norm by assuming that the social planner not only takes into account the behavioural responses of individuals induced by the social norm, but also includes the moral benefit (or cost) of participation in its measure of social welfare. In doing so, the social planner both reflects the individuals' preferences, and fully internalizes the norm's effects on redistribution and welfare. The social planner here sets and announces the optimal tax schedule first, anticipating the participation decisions of individuals. They choose whether to be active next, based on their observed tax burden relative to that of non-participants.

Note however that the planner is here either naïve or myopic as to the exact shape of the social norm function, and the possible multiplicity of equilibria. So rather than conditioning its problem on being in a given participation equilibrium, brought upon by the laissez-faire or a certain tax schedule, it conducts itself as though it were irrelevant or the equilibrium were unique. Effectively, this is equivalent to finding a local maximum, rather than choosing the global maximum. This approach will show its obvious limits when multiple equilibria are considered, in the next section.

\subsection{The social norm as a moral inducement or deterrent to participate: out- comes being attributed to luck or effort}

Let $u\left(c_{i}+x\left(h_{0}, c_{0}\right)\right)$ and $u\left(c_{0}+v_{i}\right)$ be the social utilities of type-i's when working and not working. The social utility functions are concave, and the degree of concavity reflects the planner's aversion 
to inequality. The planner's problem can be written, using $j$ instead of $i$ as a subscript in the sums:

$$
\max _{\left\{c_{0}, \cdots, c_{I}\right\}} \sum_{j>0} h_{j}\left(c_{j}-c_{0}+x\left(h_{0}, c_{0}\right)\right) u\left(c_{j}+x\left(h_{0}, c_{0}\right)\right)+\sum_{j \geq 0} \int_{v_{j} \geq \hat{v}_{j}} u\left(c_{0}+v_{j}\right) d \Gamma_{j}\left(v_{j}\right)
$$

subject to the government's budget constraint:

$$
\sum_{j>0} h_{j}\left(c_{j}-c_{0}+x\left(h_{0}, c_{0}\right)\right)\left(w_{j}-c_{j}\right)-\left(1-\sum_{j>0} h_{j}\left(c_{j}-c_{0}+x\left(h_{0}, c_{0}\right)\right)\right) c_{0}=R
$$

where $h_{0}$ satisfies (5), $R \geq 0$ is an exogenous revenue-raising requirement of taxation, and $p>0$ is the Lagrange multiplier on that constraint.

The first-order conditions (for an interior solution) with respect to $c_{i}, \forall i>0$ and $c_{0}$ are (using the fact that there is no change in utility for those changing participation choices):

$$
\begin{aligned}
h_{i} u^{\prime}\left(c_{i}+x\left(h_{0}, c_{0}\right)\right) & +\sum_{j>0} h_{j} u^{\prime}\left(c_{j}+x\left(h_{0}, c_{0}\right)\right) x_{h} \frac{\mathrm{d} h_{0}}{\mathrm{~d} c_{i}} \\
& +p\left(-h_{i}+\left(w_{i}-c_{i}+c_{0}\right) \frac{\mathrm{d} h_{i}}{\mathrm{~d} c_{i}}+\sum_{j \neq 0, i}\left(w_{j}-c_{j}+c_{0}\right) \frac{\mathrm{d} h_{j}}{\mathrm{~d} c_{i}}\right)=0, \quad \forall i>0 \\
+p\left(-\left(1-\sum_{j>0} h_{j}\left(c_{j}-c_{0}+x\left(h_{0}, c_{0}\right)\right)\right)+\sum_{j>0}\left(w_{i}-c_{i}+c_{0}\right) \frac{\mathrm{d} h_{j}}{\mathrm{~d} c_{0}}\right)=0 & \left.\left.\left.\sum_{j \geq 0} u_{v_{j} \geq \hat{v}_{j}} u^{\prime}\left(c_{0}+c_{j}\right) d \Gamma_{j}, c_{0}\right)\right) x_{c}+\sum_{j} \int_{j}\right)
\end{aligned}
$$

where, in the case of outcomes being attributed to luck:

$$
\begin{aligned}
\frac{\mathrm{d} h_{j}}{\mathrm{~d} c_{0}}= & h_{j}^{\prime}\left(-1+x_{h} \frac{\mathrm{d} h_{0}}{\mathrm{~d} c_{0}}+x_{c}\right) \gtreqless 0 \Longleftrightarrow x_{c} \gtreqless 1-x_{h} \frac{\mathrm{d} h_{0}}{\mathrm{~d} c_{0}}, c_{0}<\bar{c}_{0} \\
& <0 \text { if } c_{0}>\bar{c}_{0} .
\end{aligned}
$$

Expressed verbally, this result means that this derivative will take a positive value provided that the marginal moral benefit of compensating non-participants is superior to the change in the total incentive to not participate: i.e., the sum of the marginal change in the direct incentive $\left(\mathrm{d} c_{0} / \mathrm{d} c_{0}=\right.$ 1), and the marginal moral cost of increased non-participation times the increase in non-participants $\left(-x_{h}\left(\mathrm{~d} h_{0} / \mathrm{d} c_{0}\right)>0\right)$. This is likely to occur for low values of $c_{0}$, if, in addition, we assume $x_{c c}<0$, and $\lim _{c_{0} \rightarrow 0} x_{c}\left(h_{0}, c_{0}\right)=+\infty, \forall h_{0}>0$ : the moral benefit of compensating non-participants is strictly concave in $c_{0}$, and the marginal benefit becomes infinitely large when $c_{0}$ nears zero, as long as there are some non-participants. 
In the event where outcomes are attributed to effort, we have instead:

$$
\frac{\mathrm{d} h_{j}}{\mathrm{~d} c_{0}}=-h_{j}^{\prime}\left(1-x_{h} \frac{\mathrm{d} h_{0}}{\mathrm{~d} c_{0}}-x_{c}\right)<0, \forall c_{0}>0
$$

Any increase in $c_{0}$ therefore decreases participation, by increasing the moral cost $x(\cdot, \cdot)$ (i.e., making $x$ more negative) through an increase in both of its arguments.

Next, adopt the following definitions of the marginal social value of working type-i's consumption and moral benefits (costs), and likewise for non-participants:

$$
\tilde{g}_{i} \equiv \frac{u^{\prime}\left(c_{i}+x\left(h_{0}, c_{0}\right)\right)}{p} \forall i>0, \quad g_{0} \equiv \frac{1}{p h_{0}} \sum_{j \geq 0} \int_{v_{j} \geq \hat{v}_{j}} u^{\prime}\left(c_{0}+v_{j}\right) d \Gamma_{j}
$$

Then, using $T_{i}=w_{i}-c_{i}$, the first-order conditions can be written as follows for all $i>0$ :

$$
\left(\tilde{g}_{i}-1\right) h_{i}+\left(T_{i}-T_{0}\right) \frac{\mathrm{d} h_{i}}{\mathrm{~d} c_{i}}+\sum_{j>0} h_{j} \tilde{g}_{j} x_{h} \frac{\mathrm{d} h_{0}}{\mathrm{~d} c_{i}}+\sum_{j \neq 0, i}\left(T_{j}-T_{0}\right) \frac{\mathrm{d} h_{j}}{\mathrm{~d} c_{i}}=0
$$

and for $i=0$ :

$$
\sum_{j>0} h_{j} \tilde{g}_{j} x_{c}+\left(g_{0}-1\right) h_{0}+\sum_{j>0}\left(T_{j}-T_{0}\right) \frac{\mathrm{d} h_{j}}{\mathrm{~d} c_{0}}=0
$$

The first-order conditions on $c_{i},(10)$, can be further revised by using the following, obtained from (5) holding $c_{0}$ constant:

$$
\frac{\mathrm{d} h_{0}}{\mathrm{~d} c_{i}}=-\frac{\mathrm{d} h_{i}}{\mathrm{~d} c_{i}} \frac{1}{1+A_{i}}<0, \quad \frac{\mathrm{d} h_{j}}{\mathrm{~d} c_{i}}=\frac{\partial h_{j}}{\partial h_{0}} \frac{\mathrm{d} h_{0}}{\mathrm{~d} c_{i}}=h_{j}^{\prime} x_{h} \frac{\mathrm{d} h_{0}}{\mathrm{~d} c_{i}}>0
$$

where by (6):

$$
\frac{1}{1+A_{i}}=-\frac{\mathrm{d} h_{0}}{\mathrm{~d} h_{i}}
$$

Using these, 10 becomes:

$$
\left(1-\tilde{g}_{i}\right) h_{i}=\left(\left(T_{i}-T_{0}\right)-\frac{\sum_{j>0} h_{j} \tilde{g}_{j} x_{h}}{1+A_{i}}-\frac{\sum_{j \neq 0, i}\left(T_{j}-T_{0}\right) h_{j}^{\prime} x_{h}}{1+A_{i}}\right) \frac{\mathrm{d} h_{i}}{\mathrm{~d} c_{i}} .
$$

This can be rewritten using the definition of the total elasticity of participation $\xi_{i}$ (still holding $c_{0}$ constant) as:

$$
\frac{T_{i}-T_{0}}{c_{i}-c_{0}}=\frac{1-\tilde{g}_{i}}{\xi_{i}}+\frac{x_{h}}{c_{i}-c_{0}}\left(\frac{\sum_{j \neq 0, i}\left(T_{j}-T_{0}\right) h_{j}^{\prime}}{1+A_{i}}+\frac{\sum_{j>0} h_{j} \tilde{g}_{j}}{1+A_{i}}\right) .
$$

The optimal tax-and-transfer scheme is actually determined by all $I+1$ such first-order conditions, as a $I+1$-parameter solution of the system of equations. Nevertheless, the above formula allows us to compare the optimal tax-and-transfer schedule in the presence of a social norm underscored by two different societal views of distributive justice (luck and effort driving outcomes), with 
that of Saez (2002), given by:

$$
\frac{T_{i}-T_{0}}{c_{i}-c_{0}}=\frac{1}{\eta_{i}}\left(1-g_{i}\right)
$$

Intuitively, the Saez formula can be obtained by reasoning that at the optimum, the sum of the mechanical and behavioural effects of changing the tax levied on class $i$ must be zero. Supposing that we increase the tax by $d T_{i}$, its mechanical effect is to raise $d T_{i} h_{i}$ in revenues, while also to reduce the welfare of class $i$ by $-h_{i} g_{i} d T_{i}$. The total change in social welfare is therefore $\left(1-g_{i}\right) h_{i} d T_{i}$. Meanwhile, its behavioural effect is to induce some participants in class $i$ to drop out of the work force: this reduces revenues by $-d h_{i}\left(T_{i}-T_{0}\right)$, while leaving their welfare unaffected, by the envelope theorem. Using the fact that the elasticity of participation is $\eta_{i}=\left(\partial h_{i} / \partial\left(c_{i}-c_{0}\right)\right) \cdot\left(\left(c_{i}-c_{0}\right) / h_{i}\right)$, and that $d\left(c_{i}-c_{0}\right)=d T_{i}$, the behavioural effect is then: $-\left(\eta_{i} h_{i} d T_{i}\left(T_{i}-T_{0}\right)\right) /\left(c_{i}-c_{0}\right)$, and we can obtain equation (13).

In the presence of a social norm affecting participants, the optimal tax is intuitively determined in an analogous way. Consider first the case when outcomes are attributed to luck. The mechanical effects of a change in $T_{i}$ are identical, save for a change from $g_{i}$ to $\tilde{g}_{i}$ : the added moral benefit of participation increases utility, thus lowering marginal social utility (due to strict concavity) and the marginal social welfare weight, ceteris paribus. However, the behavioural effects are much amplified. Supposing still an increase in $T_{i}$ of magnitude $d T_{i}$, part of the behavioural effect is, as before, to induce people from class $i$ to drop out of the work force. Yet $d h_{i}<0$, by inducing $d h_{0}>0$, lowers the moral benefits $x\left(h_{0}, c_{0}\right)$, which further decreases the participation of class $i$, and that of all other classes $j>0, j \neq i$. By the envelope theorem, this has no welfare effects on those choosing to no longer work, but it does have an effect on the welfare of all remaining participants. Looking at equation 12 , the added behavioural effects enter through $\xi_{i}$ (the total participation elasticity of class $i$ ), and the terms within parentheses. The first of those represents the supplemental tax income loss from increasing $d T_{i}$, induced by lower participation in all other classes $j>0$. The second is the welfare loss of all remaining participants in classes $j \neq 0, i$. Both terms within parentheses are positive (recall that $1+A_{i}>0$, and $h_{j}^{\prime}\left(c_{j}-c_{0}+x\left(h_{0}, c_{0}\right)\right)>0$ ), but are multiplied by $x_{h} /\left(c_{i}-c_{0}\right)$. Since $x_{h}<0$ and because it is expected that $c_{i}-c_{0}>0$ for all $i>0$, this factor is negative. It follows that, ceteris paribus and relative to the Saez case, the optimal tax $T_{i}$ will be lower in the presence of a social norm entering positively in the utility of participants.

In the case where the social norm still affects participants, but instead reflects the view that economic outcomes are due to effort, the behavioural effects are nearly identical to the description above, save for a few differences. First, the moral benefit $x\left(h_{0}, c_{0}\right)$ should be interpreted as a moral cost instead. Second, the effect on weights is such that $\tilde{g}_{i}>g_{i} \forall i>0$ : the marginal utility of participants is higher, due to $x(\cdot, \cdot)<0$. Third, the elasticity of participation $\xi_{i}$ is now unambiguously greater than in the absence of norms $\left(\eta_{i}\right)$. Lastly, $x_{h}$ is lower than when outcomes are attributed to luck, ceteris paribus, due to $x_{c h}<0$ instead of $x_{c h}>0$ in the case of luck.

These results may also be restated in terms of participation tax rates. Defining $t_{i} \equiv\left(T_{i}-T_{0}\right) / w_{i}$ as the participation tax rate on class $i$, we obtain the Saez case: 


$$
\frac{t_{i}}{1-t_{i}}=\frac{1-g_{i}}{\eta_{i}}
$$

while the optimal participation tax rate in the presence of a moral benefit (or cost) accruing to participants can be written:

$$
\frac{1}{1-t_{i}}\left[t_{i}-\frac{x_{h}}{w_{i}}\left(\frac{\sum_{j \neq 0, i} h_{j}^{\prime} w_{j} t_{j}}{\left(1+A_{i}\right)}+\frac{\sum_{j>0} h_{j} \tilde{g}_{j}}{1+A_{i}}\right)\right]=\frac{1-\tilde{g}_{i}}{\xi_{i}}
$$

These results are summarized in the proposition below.

Proposition 1. For identical social weights $g_{i}=\tilde{g}_{i}$, and identical elasticities of participation $\eta_{i}=\xi_{i}$, the optimal tax schedule prescribes lower participation taxes in the presence of a social norm acting either as a moral benefit or cost for participants, compared to without.

Corollary 1. When the moral benefit or cost falls on participants, optimal participation taxes are higher when the social norm reflects the view that outcomes are attributed to luck, rather than effort, ceteris paribus. This is attributable to lower welfare weights $\tilde{g}_{i}$ on participants, lower elasticities $\xi_{i}$, and a greater value of $x_{h}$ all prevailing in the case of luck.

While the proposition above, in order to obtain a clear result, assumes that marginal social welfare weights are the same when norms are present as when they are not, it is hardly so. In the case of a norm embodying the view that outcomes are dictated by luck, the weights on all working classes will be lower, for a given system of taxes and transfers; this alone calls for higher participation taxes when the norm is present. The opposite result holds when the norm is based on the view that outcomes are the product of effort.

The result outlined in Proposition 1 also crucially depends on the assumption that the elasticities of participation be identical both when a social norm is present and when it is not. In general, the greater is the elasticity of labour participation for group $i$, the lesser is the potential for redistribution towards non-participants. The volatility of participation is greater in the presence of a social norm than in its absence, but so can be overall participation (when outcomes are attributed to luck) because of the incitement to co-operate that benefits participants. This implies that the elasticities of participation may or may not be greater in the presence of a social norm than in its absence (when outcomes are attributed to luck), which has ambiguous implications for redistribution. (In contrast, the elasticity of participation is unambiguously greater when outcomes are put down to effort, which should, ceteris paribus, call for lower participation taxes than in the Saez case, and also relative to the other extreme view of distributive justice.)

Finally, the above corollary is of some importance too, for it reflects how societal attitudes towards redistribution affecting labour market participation can be taken into account by the social planner, through generalized welfare weights, without necessarily explicitly being part of the social welfare function (for related work in this regard, see Saez and Stantcheva, 2013). 


\subsection{The social norm as a moral cost for non-participants: outcomes being at- tributed to effort}

If the social norm reflects the view that outcomes are attributable to effort, but is instead included as a moral cost for non-participants rather than a benefit for participants, then $u\left(c_{i}\right)$ and $u\left(c_{0}+\right.$ $\left.v_{i}+x\left(h_{0}, c_{0}\right)\right)$ are the social utilities of type-i's when working and not working, and the shares $h_{i}$ can be rewritten as $h_{i}\left(c_{i}-c_{0}-x\left(h_{0}, c_{0}\right)\right)$. Defining:

$$
\tilde{g}_{0} \equiv \frac{1}{p h_{0}} \sum_{j \geq 0} \int_{v \geq \hat{v}_{j}} u_{j}^{\prime}\left(c_{0}+v_{j}+x\left(h_{0}, c_{0}\right)\right) d \Gamma_{j}
$$

to represent the new marginal social weight put on the non-participating group, and following the preceding steps, we obtain then ${ }^{6}$

$$
\frac{T_{i}-T_{0}}{c_{i}-c_{0}}=\frac{1-g_{i}}{\xi_{i}}-\frac{x_{h}}{c_{i}-c_{0}}\left(\frac{\sum_{j \neq 0, i}\left(T_{j}-T_{0}\right) h_{j}^{\prime}}{1-A_{i}}-\frac{\tilde{g}_{0} h_{0}}{1-A_{i}}\right) .
$$

When comparing the resulting formula with that of Saez, the intuition remains the same as for when the social norm is modelled as a moral inducement or deterrent for participants, save for the behavioural effects of a change in $T_{i}$. Instead of lowering the utility of participants, an increase in $h_{0}$ increases that of non-participants (already given a greater weight $\tilde{g}_{0}>g_{0}$, due to the moral cost of non-participation lowering their utility, and thus increasing the marginal social utility, ceteris paribus). Thus, while the first term within parentheses in equation (14) is otherwise identical to when the norm affects participants, the second differs, especially in its sign: it is negative. It is therefore no longer clear what sign the added terms take, so that relative to the Saez case, and ceteris paribus, the optimal tax $T_{i}$ could be higher in the presence of a social norm entering negatively in the utility of non-participants.

${ }^{6}$ This is so since the first-order condition with respect to $c_{i}$ is now:

$$
\begin{gathered}
h_{i} u^{\prime}\left(c_{i}\right)+\sum_{j \geq 0} \int_{v \geq \hat{v}_{j}} u_{j}^{\prime}\left(c_{0}+v_{j}+x\left(h_{0}, c_{0}\right)\right) d \Gamma_{j} x_{h} \frac{\mathrm{d} h_{0}}{\mathrm{~d} c_{i}} \\
+p\left(-h_{i}+\left(w_{i}-c_{i}+c_{0}\right) \frac{\mathrm{d} h_{i}}{\mathrm{~d} c_{i}}+\sum_{j \neq 0, i}\left(w_{j}-c_{j}+c_{0}\right) \frac{\mathrm{d} h_{j}}{\mathrm{~d} c_{i}}\right)=0, \quad \forall i>0
\end{gathered}
$$

where, since $h_{i}\left(c_{i}-c_{0}-x\left(h_{0}, c_{0}\right)\right)$ :

$$
\frac{\mathrm{d} h_{0}}{\mathrm{~d} c_{i}}=-\frac{\mathrm{d} h_{i}}{\mathrm{~d} c_{i}} \frac{1}{1-A_{i}}<0, \quad \frac{\mathrm{d} h_{j}}{\mathrm{~d} c_{i}}=\frac{\partial h_{j}}{\partial h_{0}} \frac{\mathrm{d} h_{0}}{\mathrm{~d} c_{i}}=-h_{j}^{\prime} x_{h} \frac{\mathrm{d} h_{0}}{\mathrm{~d} c_{i}}>0
$$

This therefore reduces to:

$$
\left(1-g_{i}\right) h_{i}=\left(\left(T_{i}-T_{0}\right)-\frac{h_{0} \tilde{g}_{0} x_{h}}{1-A_{i}}+\frac{\sum_{j \neq 0, i}\left(T_{j}-T_{0}\right) h_{j}^{\prime} x_{h}}{1-A_{i}}\right) \frac{\mathrm{d} h_{i}}{\mathrm{~d} c_{i}}
$$

and the result follows. 
The optimal participation tax rate with a moral cost of non-participation can also be written:

$$
\frac{1}{1-t_{i}}\left[t_{i}+\frac{x_{h}}{w_{i}}\left(\frac{\sum_{j \neq 0, i} h_{j}^{\prime} w_{j} t_{j}}{1-A_{i}}-\frac{\tilde{g}_{0} h_{0}}{1-A_{i}}\right)\right]=\frac{1-g_{i}}{\xi_{i}} .
$$

The proposition below summarizes this result.

Proposition 2. For identical social weights $g_{i}=\tilde{g}_{i}$, and identical elasticities of participation $\eta_{i}=\xi_{i}$, the effect of a social norm entering as a moral cost for non-participants, reflecting stigma brought upon by outcomes being attributed to effort, is ambiguous. There is a higher participation tax imposed on the active members of skill class $i$ whenever:

$$
\sum_{j \neq 0, i} h_{j}^{\prime} w_{j} t_{j}-\tilde{g}_{0} h_{0}<0
$$

That is to say, when the welfare loss incurred as a result of the moral stigma attached to idleness is sufficiently large and/or when there are relatively small feedback effects from the social norm, and thus redistribution from class $i$ towards non-participants can be done at a low budgetary cost.

We thus have derived the optimal redistributive tax schedule in the presence of a social norm, and established in what circumstances it leads to a higher or lower scope for redistribution (i.e., participation tax) than in its absence. Yet while the above results illustrate what a naïve social planner might choose to implement, irrespective of the economy's initial participation equilibrium in the laissez-faire or in the presence of another initial sub-optimal tax schedule, they do not fully describe the possibility for the existence of multiple participation equilibria, and their desirability. The normative implications of the existence of participation equilibria, and the planner incorporating in its optimal tax problem a concern for societal cohesion, are considered next. Throughout what follows, it is assumed that the tax system is progressive, although that is not a necessary implication of the optimal tax analysis above.7

\footnotetext{
${ }^{7}$ The optimal tax formula in the Saez model can be written as:

$$
\frac{T_{i}-T_{0}}{c_{i}-c_{0}}=\frac{T_{i}-T_{0}}{w_{i}-T_{i}+T_{0}}=\frac{\left(T_{i}-T_{0}\right) / w_{i}}{1-\left(T_{i}-T_{0}\right) / w_{i}}=\frac{1-g_{i}}{\eta_{i}}
$$
}

Let $t_{i} \equiv\left(T_{i}-T_{0}\right) / w_{i}$ denote the participation tax rate. Suppose $\eta_{i}=\eta$ for all $i$. Then, comparing groups $i$ and $i-1$ :

$$
\frac{t_{i}}{1-t_{i}}-\frac{t_{i-1}}{1-t_{i-1}}=\frac{g_{i-1}-g_{i}}{\eta}>0
$$

Therefore, $t_{i}>t_{i-1}$, or:

$$
\frac{T_{i}-T_{0}}{w_{i}}>\frac{T_{i-1}-T_{0}}{w_{i-1}} \Longrightarrow \frac{T_{i}}{w_{i}}-\frac{T_{i-1}}{w_{i-1}}>T_{0}\left(\frac{1}{w_{i}}-\frac{1}{w_{i-1}}\right)<0
$$




\section{The welfare state, the extent of redistribution, and norms-based societal consensus}

Certain authors (e.g., Murray, 1984, cited by Barr, 2004, p. 357; Skidelsky, 1997) have suggested that redistribution programs linked to the welfare state lead to a "culture of poverty". This culture is the product of overly generous benefits leading to heightened moral hazard, thus compounding the economic problem they were supposed to solve by increasing idleness and dependency. This argument is by no means universally accepted, nor is it new: similar arguments were heard as early as the dawn of the 19th century, for instance in Jeremy Bentham's characterization of the 1834 Poor Laws as "causing moral degeneracy among recipients" (Barr, 2004, p. 17). Yet it is one still sketched by critics of the welfare state, for instance as recently expressed by Robert Skidelsky (Skidelsky, 1997, pp. 9-10, emphasis added):

The Welfare State creates all kinds of moral traps. The 'poverty trap' is the main example: William Beveridge once shocked his listeners by saying that it was rational for someone to claim the dole if he could get more from it than by working. But moral hazard analysis can be used to illuminate many other 'welfare state' situations. It may be a rational strategy to move house to a catchment area of a desirable maintained school in order to avoid school fees, or for a mother to withdraw from the labour market so as to bring the family income within the qualifying limits for an assisted place at an independent school [...]. Social life is riddled with moral hazard. Its potential cost is huge; it is destructive of morality; and it is the duty of wise legislation to minimize it. The central argument of this essay [...] is that the Welfare State, setting out to minimise moral hazard through social insurance, has made it endemic.

While the scope of the policies identified in the quote above goes beyond this paper's, the general idea contained therein is nevertheless pertinent, especially the claim that redistributive policies are "destructive of morality". This phrase goes beyond the simple idea of increased moral hazard, implying instead that the very extent of societal cohesion - i.e., co-operation between individuals arising out of incitements to avoid self-interested behaviour - is imperiled by the welfare state and its redistributive programs. Rather than fostering social cohesion through social insurance, redistributive policies upon which the welfare state rests would, by this logic, instead lead to the very opposite: the payment of transfers to the (relatively many) unemployed being made by the (relatively few) working individuals. This would constrain the possible scope of redistribution, through the progressive reduction of the inducements to co-operate, or of the social stigma associated with receiving transfers, which eventually come to be viewed as entitlements. In effect, this is a re-framing of the age-old equity-efficiency debate, with the additional feature that the behaviours of others matter in the making of one's decision to either be an active member of society, or to remain idle. Such more sophisticated views of the welfare state's effect on social norms were first voiced by Lindbeck (1995), then modelled successively by numerous authors. Lindbeck (1996, p. 6) 
summarizes this line of thinking thus:

Strong macroeconomic shocks during the last two decades have also 'thrown' many citizens onto various safety nets, where they have remained for long periods of time in Western Europe. It is tempting to hypothesize that this has weakened previously dominating social norms against living off various welfare-state benefits. Long term negative effects on labor-force participation and aggregate unemployment are obvious consequences (Lindbeck, 1995).

Our framework allows for an analysis of such a conjecture, by including the possibility of multiple equilibria in participation and by thus characterizing the scope of redistributive policies compatible with a high participation of the labour force, given a social norm embodying a view of distributive justice.

The following subsections therefore consider the optimality of redistributive taxation in light of the possibility of multiple equilibria in participation. After a presentation of the basic mechanism through which the tax system affects equilibrium choice, it considers the maximum progressivity of the tax system that can be implemented by a social planner without triggering an adverse shift in participation equilibria. It then asks if it can be worthwhile (i.e., Pareto-improving) from a social welfare perspective to shock the system through changes in the tax system, so as to engineer a shift in participation equilibria, from low to high participation; this, even if this initial shift goes against the planner's (or political party's) objective function.

\subsection{Conditioning the planner's problem on the participation equilibrium's prop- erties}

In what follows, we consider two cases: first, that of the economy being in a high-participation equilibrium; second, that of a low-participation one. The former is not terribly constraining for the social planner: starting at such an equilibrium, implementing a certain optimal redistributive tax schedule requires being careful not to trigger a shift to a low-participation equilibrium. We therefore characterize the maximum degree of tax progressivity compatible with a high-participation equilibrium. In the latter case, we instead first look at how the social planner may trigger a shift in equilibria, then discuss the welfare properties of such a shift, and the circumstances under which the social planner may undertake it. The analysis culminates with an optimal tax problem in which the planner fully takes into account the nature of the participation function induced by the norm, the initial equilibrium, and the desirability of a shift in equilibria. 


\subsection{1 "Optimistic selection": The maximum degree of progressivity compatible with a high-participation equilibrium}

Recall that the social norm determines the equilibrium level of participation according to equation:

$$
h_{0}^{+}=1-\sum_{i \neq 0} h_{i}\left(c_{i}-c_{0}+x\left(h_{0}, c_{0}\right)\right)
$$

This equation depends upon three characteristics of the system, that determine the $h_{i}$ function's shape and position: the shape of the c.d.f. of the preferences for leisure, $\Gamma_{i}\left(v_{i}\right)$; the characteristics of the moral benefit function, $x\left(h_{0}, c_{0}\right)$; and the tax system, $\left\{T_{i}\right\}_{i=0}^{I}$. In what follows, we sometimes simplify the distribution of preferences for leisure by choosing a particular uniform distribution, as in Subsection 2.3 on page 10. This allows us to focus on the role of the social norm.

Consider a situation where there are two possible equilibria, one characterized by low participation, $h_{0}^{\star \star}$, and one characterized by high participation, $h_{0}^{\star}, h_{0}^{\star \star}>h_{0}^{\star}$. Starting at $h_{0}^{\star}$, comparative statics with respect to consumption (resp. taxes) show how the participation curve shifts, with a possible change in its curvature:

$$
\frac{\partial h_{0}^{+}\left(\mathbf{c}, h_{0}^{\star}\right)}{\partial c_{i}} \mathrm{~d} c_{i}=-h_{i}^{\prime}\left(c_{i}-c_{0}+x\left(h_{0}^{\star}, c_{0}\right)\right) \mathrm{d} c_{i}
$$

Graphically, this means that the participation curve will shift upwards if $\mathrm{d} c_{i}<0$ (resp. $\mathrm{d} T_{i}>$ 0 ), implying a decrease in the participation of class $i$ resulting from decrease in its equilibrium consumption when active. Once the feedback effects of the social norm are felt through the other classes, and the new equilibrium $h_{0}^{\star \prime}$ is achieved (cf. Figure 2 , below), it is characterized by a lower level of labour force participation.

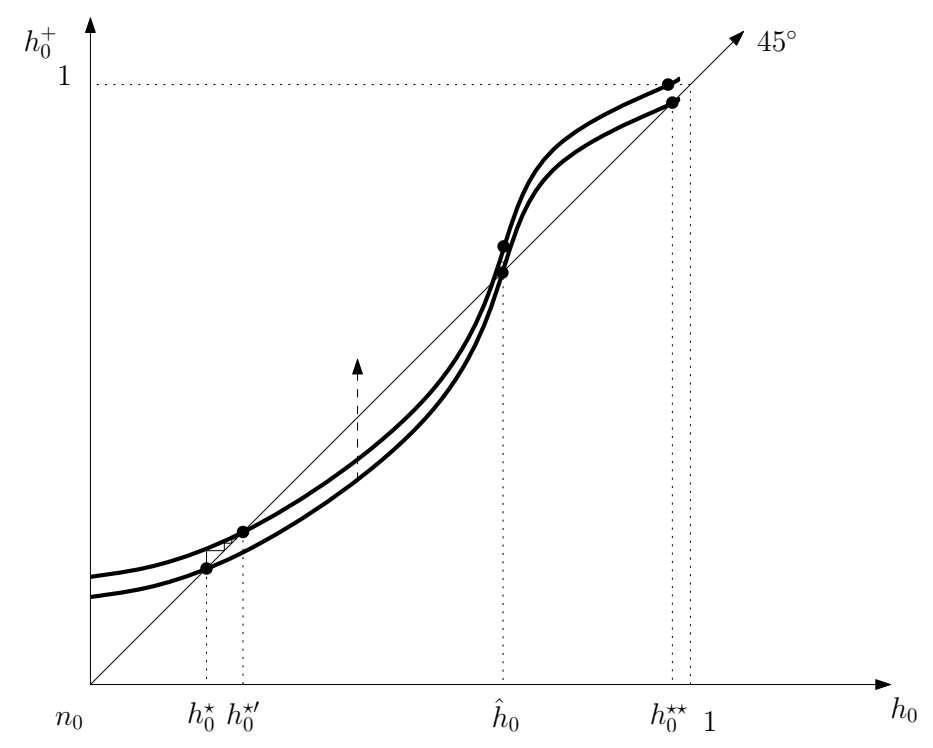

Figure 2: Comparative statics with respect to $c_{i}$ and its effects on the participation curve 
It appears that a large-enough change could trigger a shift from a high- to a low-participation equilibrium, through the mechanisms outlined by Lindbeck 1995, 1996). This would occur technically here through the disappearance of the high-participation equilibrium, triggered by an upward shift or rotation of the curve for $h_{0}^{+}\left(h_{0}\right)$, so that only the low-participation equilibrium subsists. For this to happen, the participation curve would need to lie everywhere above the $45^{\circ}$ line in the range where it once included a high-participation equilibrium, as shown below.

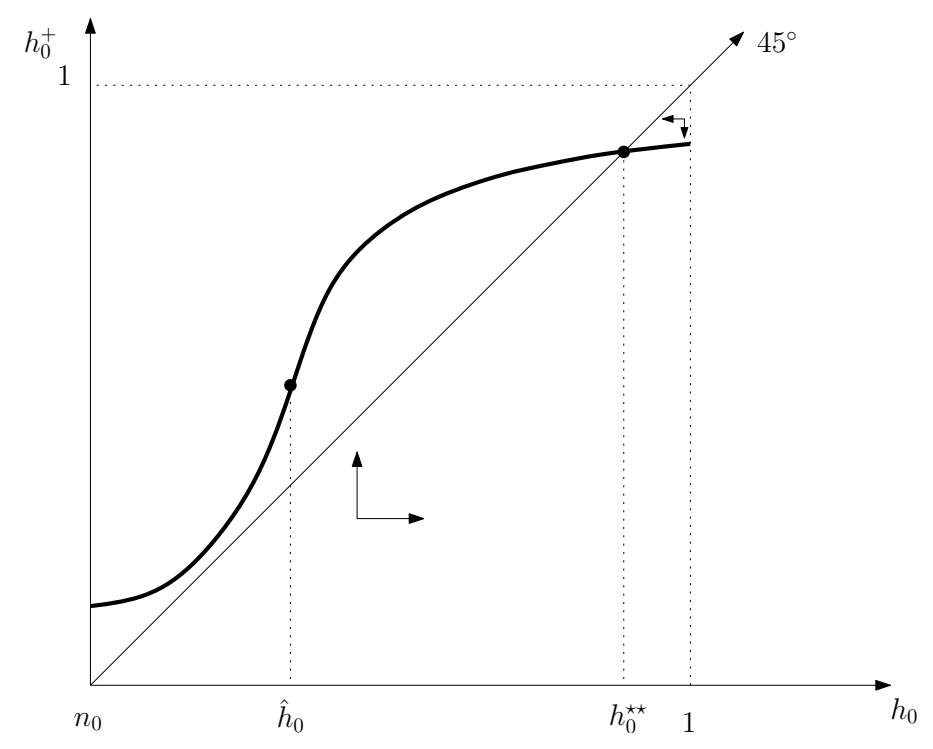

Figure 3: The disappearance of the high-participation equilibrium

The progressivity of the tax system, and the corresponding extent of redistribution, is constrained by the individuals' degree of participation in the labour force, as measured by the elasticity of participation of each skill class. Furthermore, a social planner (or party in power) may also particularly be concerned with large negative, spiralling feedback effects, and try to avoid a shift from a high- to a low-participation equilibrium, for greater progressivity would then be adversely mitigated by a small tax base and low absolute transfer levels.

Starting in a high-participation equilibrium, for any given (sub-optimal) tax schedule, it may therefore seek to increase the progressivity of the income tax schedule according to its social objective. This can be done up to a point, beyond which a participation "regime shift" occurs. At such a point, a regime-shift constraint is exactly binding: this happens where the lower part of the participation curve (below the inflection point) becomes tangent to the $45^{\circ}$ line. This assumes that the tax burden of enough skill classes increases, and is not offset by decreases in the burden of other classes, so that overall participation declines, but does not spiral upwards uncontrollably. Graphically, this yields: 


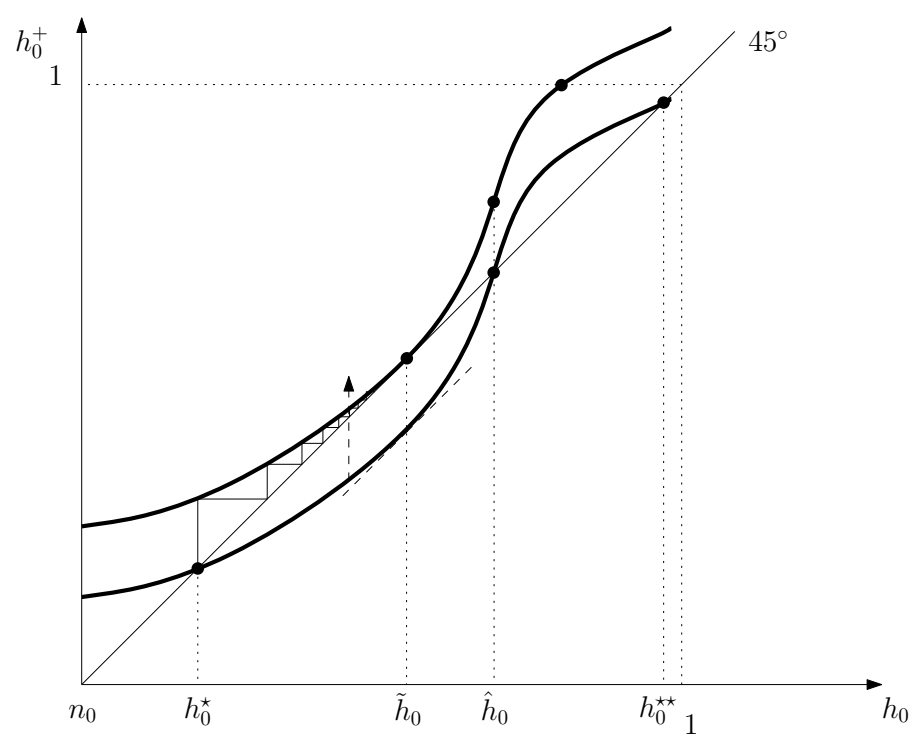

Figure 4: The maximum increase in progressivity compatible with a high-participation equilibrium

Formally, just how large a change in consumption bundles is needed to avoid triggering such a shift in equilibrium generally depends on its effects on both the curvature of the function $h_{0}^{+}\left(h_{0}\right)$ (i.e., its slope and concavity), and on its level in the $h_{0}-h_{0}^{+}$space. For illustrative purposes, let us focus on the case where the change in consumption bundles causes a parallel upward shift in the curve of $h_{0}^{+}\left(h_{0}\right)$, that is, where the curvature of the function is left unchanged as a result of the shock. This corresponds to the case where preferences for leisure are uniformly distributed within each skill class, since in that case, $h_{i}^{\prime}\left(c_{i}-c_{0}+x\left(h_{0}, c_{0}\right)\right)$ is a constant.

Starting from $h_{0}^{\star}$, the maximum magnitude of the changes is determined thus:

1. Find the range for which the curve needs to be completely over the $45^{\circ}$ line (and is not initially), for only the low-participation equilibrium to subsist;

2. Find the point $\tilde{h}_{0}$ where $\tilde{h}_{0}-h_{0}^{+}\left(\tilde{h}_{0}\right)$ is greatest, in that range;

3. Find the magnitude $\tilde{h}_{0}-h_{0}^{+}\left(\tilde{h}_{0}\right)-\epsilon, \epsilon>0$.

According to Figure 4, the range for which the function $h_{0}^{+}$needs to be raised above the $45^{\circ}$ line is $h_{0} \in\left[h_{0}^{\star}, \hat{h}_{0}\right]$, where $\hat{h}_{0}$ is the inflection point. Hence, at that point:

$$
\frac{\mathrm{d}^{2} h_{0}^{+}}{\mathrm{d} h_{0}^{2}}=0 \Longleftrightarrow-\sum_{i \neq 0}\left(h_{i}^{\prime \prime}(\cdot)\left(x_{h}\right)^{2}+h_{i}^{\prime} x_{h h}\right)=0 .
$$

In the case of uniformly-distributed preferences for leisure, this reduces to:

$$
\hat{h}_{0}: \quad x_{h h}\left(\hat{h}_{0}, c_{0}\right)=0 .
$$

thus pinning down more explicitly the range's upper limit, its lower limit being one of the solutions of the equation $h_{0}^{+}\left(h_{0}\right)=h_{0}$. Second, the point where $\tilde{h}_{0}-h_{0}^{+}(\tilde{h})$ is greatest in that range corresponds 
to the point where the slope of the tangent to $h_{0}^{+}$is equal to that of the $45^{\circ}$ line. (This can also be found as the solution to the first-order condition of the maximization problem of $\tilde{h}_{0}-h_{0}^{+}\left(\tilde{h}_{0}\right)$ with respect to $\tilde{h}_{0}$.) This yields:

$$
\frac{\mathrm{d} h_{0}^{+}\left(\tilde{h}_{0}\right)}{\mathrm{d} h_{0}}=1 \Longleftrightarrow-\sum_{i \neq 0} h_{i}^{\prime}(\cdot) x_{h}\left(\tilde{h}_{0}, c_{0}\right)=1
$$

Supposing that all consumption bundles are affected by taxes, the total magnitude of the shift is given by:

$$
\frac{\partial h_{0}^{+}\left(\mathbf{c}, h_{0}^{\star}\right)}{\partial c_{0}} \mathrm{~d} c_{0}+\sum_{i \neq 0} \frac{\partial h_{0}^{+}\left(\mathbf{c}, h_{0}^{\star}\right)}{\partial c_{i}} \mathrm{~d} c_{i}=\sum_{i \neq 0} h_{i}^{\prime}(\cdot)\left(\left(1-x_{c}\left(h_{0}^{\star}, c_{0}\right)\right) \mathrm{d} c_{0}-\mathrm{d} c_{i}\right)
$$

which must satisfy:

$$
\tilde{h}_{0}-h_{0}^{+}\left(\tilde{h}_{0}\right)-\epsilon=\sum_{i \neq 0} h_{i}^{\prime}\left(c_{i}-c_{0}-x\left(h_{0}^{\star}, c_{0}\right)\right)\left(\left(1-x_{c}\left(h_{0}^{\star}, c_{0}\right)\right) \mathrm{d} c_{0}-\mathrm{d} c_{i}\right) .
$$

\subsection{2 "Pessimistic selection": A shift from a low-participation to a high-participation equilibrium using the tax system}

Let us now examine the transition from a low- to a high-participation equilibrium. As the comparative statics considered above made apparent, a marked downwards shift in the participation curve can most likely be achieved through an initial decrease in the progressivity of the tax schedule. What is consequently needed is a decrease in the tax burden of most skill classes with the exception of class 0 , and especially the tax burden of those naturally more inclined to participate (i.e., those with the greatest elasticity of participation). This initial impulse will feed back afterwards through the social norm until a high-participation equilibrium is reached. Only once is this high-participation equilibrium reached can a return to a higher level of progressivity be considered. It may be that at a high-participation equilibrium, the increase in tax revenues induced by higher participation allows for more progressivity than before, and a higher level of transfers.

To get a glimpse of what this implies from a social planning and political-economic point of view, suppose for instance that corrupted moral incitements to co-operate have shifted the economy from a high- to a low-participation equilibrium. Preventing the long-term idleness of a greater portion of the population would therefore require an initial decrease in the progressivity of the tax system. This may have adverse (electoral, and other) consequences for the party in power, especially if that party is characterized by a strong ideological aversion to inequality. Voters may not be as far-sighted as the party in power, and the transition to a high-participation equilibrium may prove to be slow, therefore hindering a return to a higher level of income tax progressivity. Even from a social planner's perspective, it is not clear that this solution is always desirable. The initial social costs of reducing progressivity may never be adequately compensated, also here because of 
the length of the transition or the near-sightedness of individuals. Subsection 4.1 .3 considers in more detail the desirability of a shift from a low- to a high-participation equilibrium, while related political-economic issues are discussed in Section 5 .

Returning to our characterization of the required impulse for there to be a transition, the figure below represents the minimal downwards shift in the participation curve necessary for a shift in participation equilibria:

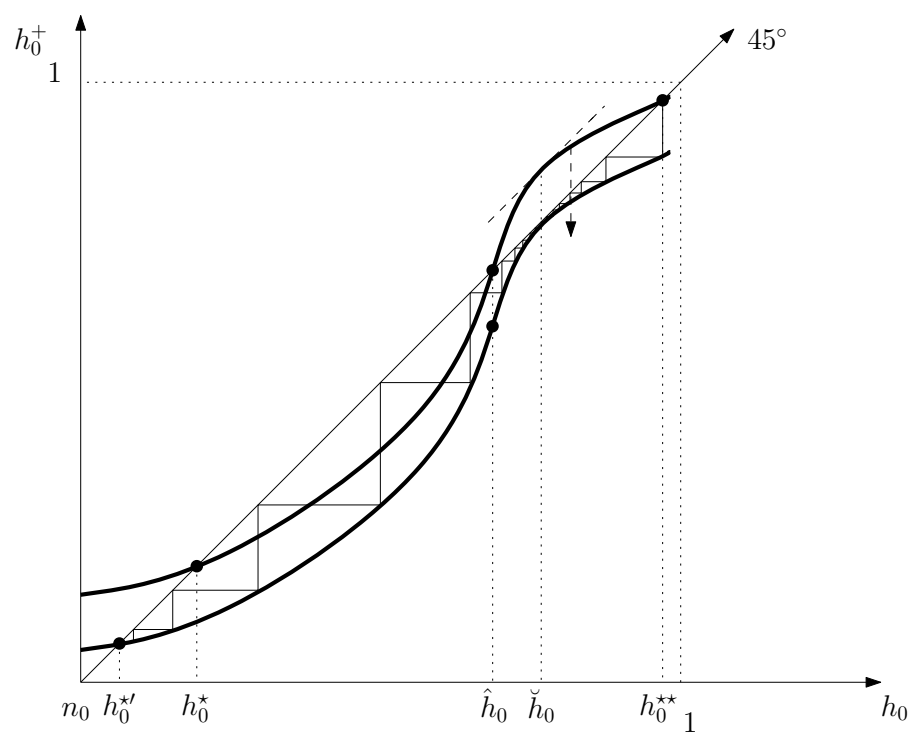

Figure 5: A shift from a low- to a high-participation equilibrium

The required magnitude of that shift can be characterized by following these few steps, which match our earlier approach to the question of the curve's upwards shifts, as caused by changes in the tax system:

1. Find the range for which the curve needs to be completely under the $45^{\circ}$ line, for there to be convergence;

2. Find the point $\breve{h}_{0}$ where $h_{0}^{+}\left(\breve{h}_{0}\right)-\breve{h}_{0}$ is greatest, in that range;

3. Find the magnitude $-\left(h_{0}^{+}\left(\breve{h}_{0}\right)-\breve{h}_{0}+\epsilon\right), \epsilon>0$.

\subsubsection{The welfare properties of a shift from a low- to a high-participation equilibrium}

This begs the question of the desirability of certain participation equilibrium outcomes, and what can be done about achieving them. Should the social planner or party in office seek to trigger a shift from a low- to a high-participation equilibrium, even if this initial shift runs counter to certain ideological views, or an aversion to inequality?

When the social norm acts as an moral inducement or deterrent affecting participants (when the norm reflects the view that outcomes are attributable to luck or to effort, respectively), a move 
from a low- to a high-participation equilibrium can be Pareto-improving. Recall that the required change in taxation for a transition to occur is given by:

$$
\sum_{i \neq 0} h_{i}^{\prime}\left(c_{i}-c_{0}+x\left(h_{0}^{\star \star}, c_{0}\right)\right)\left(\mathrm{d} c_{i}-\left(1-x_{c}\left(h_{0}^{\star \star}, c_{0}\right)\right) \mathrm{d} c_{0}\right)=h^{+}\left(\breve{h}_{0}\right)-\breve{h}_{0}+\epsilon
$$

where the left-hand side represents the actual total change in taxation, and the right-hand side corresponds to its minimal required magnitude.

Consider changes in taxes affecting many groups, with not all of these changes being cuts (e.g., cuts affecting skill classes with the greatest marginal participation effect, $h_{i}^{\prime}$, but compensated for the purpose of balancing the budget or preserving to some extent the progressivity of the tax schedule by tax increases levied on certain other skill classes), but with their aggregate effect meeting the minimum required shift for there to be a convergence to a high-participation equilibrium. For the high-participation equilibrium to Pareto-dominate the low-participation equilibrium after the transition requires the following. First, it must be that for all participants of a given skill class $i$ :

$$
c_{i}+\mathrm{d} c_{i}+x\left(h_{0}^{\star \prime}, c_{0}\right) \geq c_{i}+x\left(h_{0}^{\star \star}, c_{0}\right)
$$

which must hold with strict inequality for at least one $i$. This holds trivially for $\mathrm{d} c_{i}>0$, that is for the skill classes which incur a tax cut, $\mathrm{d} T_{i}<0$. All classes for which $\mathrm{d} c_{i}<0$ must therefore satisfy in addition:

$$
x\left(h_{0}^{\star \prime}, c_{0}\right)-x\left(h_{0}^{\star \star}, c_{0}\right) \geq-\mathrm{d} c_{i}
$$

This states that the gain in inducements to co-operate obtained through the social norm must exceed the cost in terms of consumption. For all non-participants who end up participating, it trivially must be that:

$$
c_{i}+\mathrm{d} c_{i}+x\left(h_{0}^{\star \prime}, c_{0}\right) \geq c_{0}+v_{i}
$$

Across all classes $i>0$, this needs to hold for there to be a decrease in $h_{0}$ (from $h_{0}^{\star \star}$ to $h_{0}^{\star \prime}$ ). Provided that $c_{0}$ is left unchanged, then the non-participants are no worse-off. This yields the following proposition.

Proposition 3. For a shift from a low- to a high-participation equilibrium to be Pareto-improving, this shift must satisfy the following conditions. First, the initial shift must be of a sufficient magnitude to trigger the transition, i.e.:

$$
\sum_{i \neq 0} h_{i}^{\prime}\left(c_{i}-c_{0}+x\left(h_{0}^{\star \star}, c_{0}\right)\right) \mathrm{d} c_{i} \geq h^{+}\left(\breve{h}_{0}\right)-\breve{h}_{0}+\epsilon
$$

Second, it must be that:

$$
x\left(h_{0}^{\star \prime}, c_{0}\right)-x\left(h_{0}^{\star \star}, c_{0}\right) \geq \max \left\{-\mathrm{d} c_{i}\right\}_{i>0}
$$

Note that there is no easy way of determining whether this shift in equilibria is also strictly Pareto-improving during the transition from one equilibrium to the other, since our model cannot 
establish what time the transition might take. The initial loss incurred by the skill classes for whom $\mathrm{d} c_{i}<0$ might turn out to be, in terms of net present value, greater than the appropriately-discounted gains in $x\left(h_{0}, c_{0}\right)$ along the transition path.

It is also interesting to note that if the social norm is included as a moral cost for nonparticipants, again also reflecting the view that outcomes are attributable to effort, then no transition to a high-participation equilibrium from a low-participation equilibrium can be Paretoimproving if it involves some initial losers. It must therefore be solely engineered by tax cuts (hence reducing more sharply the progressivity of the income tax, and posing the question of budget balance). Let us examine why. First, if $c_{0}$ is left unchanged, as shown above, then the non-participants are definitely worse off than before because $x\left(h_{0}^{\star \prime}, c_{0}\right)<x\left(h_{0}^{\star \star}, c_{0}\right)$. Of course, they could possibly be compensated, and surely, some former non-participants who now choose to participate are at least as well off, regardless of the sign of $\mathrm{d} c_{i}$. But the main difference lies in those participants who incur a loss $\mathrm{d} c_{i}<0$ and who choose to keep on participating: the transition from $h_{0}^{\star \star}$ to $h_{0}^{\star \prime}$ then does not benefit them in any possible way that would alleviate their loss in consumption. All it does is make their outside option less attractive (i.e., there is more stigma attached to non-participation).

\subsubsection{Societal cohesion as a constraint on the social planner's choice of tax schedules}

How is the social planner or party in office then supposed to take this in stride, so as to engineer a shift in participation that matches (as much as possible) its social welfare objectives, and also constitutes a Pareto improvement? Let again $h_{0}^{\star \star}$ be the initial low-participation equilibrium, and let there be some income tax schedule in place that is consistent with budget balance (but not necessarily with whatever the social objectives of the planner or party may be) at that level of participation. This income tax schedule translates into a series of consumption bundles $\left\{c_{i}\right\}_{i=0}^{I}$. The social planner seeks therefore to choose a change in taxes and transfers - equivalent to choosing a change in consumption bundles, $\left\{\mathrm{d} c_{i}\right\}_{i=0}^{I}$ - that maximizes a social welfare function evaluated at the desired equilibrium in participation, $h_{0}^{\star}$, and subject to certain constraints. Following the derivation in Subsection 3 , this problem is generally given by:

$$
\begin{array}{r}
\left.\max _{\left\{\mathrm{d} c_{0}, \cdots, \mathrm{d} c_{I}\right\}}\right|_{h_{0}=h_{0}^{\star \prime}} \sum_{j>0} h_{j}\left(c_{j}+\mathrm{d} c_{j}-c_{0}-\mathrm{d} c_{0}+x\left(h_{0}, c_{0}+\mathrm{d} c_{0}\right)\right) u\left(c_{j}+\mathrm{d} c_{j}+x\left(h_{0}, c_{0}+\mathrm{d} c_{0}\right)\right) \\
+\sum_{j \geq 0} \int_{v_{j} \geq \hat{v}_{j}} u\left(c_{0}+\mathrm{d} c_{0}+v_{j}\right) d \Gamma_{j}\left(v_{j}\right)
\end{array}
$$


s.t.

$$
\begin{aligned}
\sum_{j>0} h_{j}^{\prime}\left(c_{j}-c_{0}+x\left(h_{0}^{\star \star}, c_{0}\right)\right) \mathrm{d} c_{j} & \geq h^{+}\left(\breve{h}_{0}\right)-\breve{h}_{0}+\epsilon \\
-\left(x\left(h_{0}^{\star \prime}, c_{0}+\mathrm{d} c_{0}\right)-x\left(h_{0}^{\star \star}, c_{0}+\mathrm{d} c_{0}\right)\right) & \leq \mathrm{d} c_{j} \quad \forall j>0 \\
\mathrm{~d} c_{0} & \geq 0 \\
\sum_{j>0} h_{j}\left(c_{j}+\mathrm{d} c_{j}-c_{0}-\mathrm{d} c_{0}+x\left(h_{0}, c_{0}+\mathrm{d} c_{0}\right)\right)\left(w_{j}-c_{j}-\mathrm{d} c_{j}\right) & \\
-\left(1-\sum_{j>0} h_{j}\left(c_{j}+\mathrm{d} c_{j}-c_{0}-\mathrm{d} c_{0}+x\left(h_{0}, c_{0}+\mathrm{d} c_{0}\right)\right)\right)\left(c_{0}+\mathrm{d} c_{0}\right) & =R
\end{aligned}
$$

The first constraint specifies the required magnitude of the shift, the second and third constraints ensure the Pareto-dominance of the resulting equilibrium, and the last constraint guarantees budget balance at the new participation equilibrium. The second series of constraints being positivity constraints on $\left(\mathrm{d} c_{j}-x\left(h_{0}^{\star \star}, c_{0}\right)+x\left(h_{0}^{\star}, c_{0}\right)\right)$ for all $j>0$, and the third constraint being a positivity constraint on $\mathrm{d} c_{0}$, they do not require Lagrange multipliers, only modified first-order conditions.

The first-order conditions to the problem with respect to $\mathrm{d} c_{i}, \forall i>0$ yield:

$$
\begin{gathered}
\left(\mathrm{d} c_{i}-x\left(h_{0}^{\star \star}, c_{0}+\mathrm{d} c_{0}\right)+x\left(h_{0}^{\star \prime}, c_{0}+\mathrm{d} c_{0}\right)\right)\left[h_{i} u_{i}^{\prime}\left(c_{i}+\mathrm{d} c_{i}+x\left(h_{0}^{\star \prime}, c_{0}+\mathrm{d} c_{0}\right)\right)+\right. \\
\sum_{j>0} h_{j} u_{j}^{\prime}\left(c_{j}+\mathrm{d} c_{j}+x\left(h_{0}^{\star \prime}, c_{0}+\mathrm{d} c_{0}\right)\right) x_{h} \frac{\mathrm{d} h_{0}}{\mathrm{~d} c_{i}}+\lambda h_{i}^{\prime}\left(c_{j}-c_{0}+x\left(h_{0}^{\star \star}, c_{0}\right)\right) \\
\left.+p\left(-h_{i}+\left(w_{i}-c_{i}-\mathrm{d} c_{i}+c_{0}+\mathrm{d} c_{0}\right) \frac{\mathrm{d} h_{i}}{\mathrm{~d} c_{i}}+\sum_{j \neq 0, i}\left(w_{j}-c_{j}-\mathrm{d} c_{j}+c_{0}+\mathrm{d} c_{0}\right) \frac{\mathrm{d} h_{j}}{\mathrm{~d} c_{i}}\right)\right]=0 .
\end{gathered}
$$

Similarly, the first-order condition with respect to $\mathrm{d} c_{0}$ is given by:

$$
\begin{array}{r}
\mathrm{d} c_{0} \cdot\left[\sum _ { j > 0 } h _ { j } u ^ { \prime } \left(c_{j}+\mathrm{d} c_{j}+x\left(h_{0}^{\star \prime}, c_{0}+\mathrm{d} c_{0}\right) x_{c}+\sum_{j \geq 0} \int_{m \geq \hat{m}_{j}} u^{\prime}\left(c_{0}+\mathrm{d} c_{0}+v_{j}^{m}\right) d \Gamma_{j}\right.\right. \\
\left.+p\left(-\left(1-\sum_{j>0} h_{j}\left(c_{j}+\mathrm{d} c_{j}-c_{0}-\mathrm{d} c_{0}+x\left(h_{0}^{\star \prime}, c_{0}+\mathrm{d} c_{0}\right)\right)\right)+\sum_{j>0}\left(w_{i}-c_{i}-\mathrm{d} c_{i}+c_{0}+\mathrm{d} c_{0}\right) \frac{\mathrm{d} h_{j}}{\mathrm{~d} c_{0}}\right)\right]=0 .
\end{array}
$$

where we have, in the event of outcomes being attributed to luck:

$$
\begin{aligned}
\frac{\mathrm{d} h_{j}}{\mathrm{~d} c_{0}}= & h_{j}^{\prime}\left(-1+x_{h} \frac{\mathrm{d} h_{0}}{\mathrm{~d} c_{0}}+x_{c}\right) \gtreqless 0 \Longleftrightarrow x_{c} \gtreqless 1-x_{h} \frac{\mathrm{d} h_{0}}{\mathrm{~d} c_{0}}, c_{0}<\bar{c}_{0} \\
& <0 \text { if } c_{0}>\bar{c}_{0}
\end{aligned}
$$

and when they are attributed to effort:

$$
\frac{\mathrm{d} h_{j}}{\mathrm{~d} c_{0}}=-h_{j}^{\prime}\left(1-x_{h} \frac{\mathrm{d} h_{0}}{\mathrm{~d} c_{0}}-x_{c}\right)<0, \forall c_{0}>0 .
$$


Simplifying these equations in a manner identical to that pursued in the context of the basic optimal tax problem yields, for all $i>0$ :

$$
\begin{aligned}
\frac{T_{i}-T_{0}+\mathrm{d} T_{i}-\mathrm{d} T_{0}}{c_{i}-c_{0}+\mathrm{d} c_{i}-\mathrm{d} c_{0}} \leq & \frac{1-\tilde{g}_{i}}{\xi_{i}}-\frac{\lambda}{p \xi_{i}} h_{i}^{\prime}\left(c_{j}-c_{0}+x\left(h_{0}^{\star \star}, c_{0}\right)\right) \\
& +\frac{x_{h}}{c_{i}-c_{0}+\mathrm{d} c_{i}-\mathrm{d} c_{0}}\left(\frac{\sum_{j>0} h_{j} \tilde{g}_{j}}{1+A_{i}}\right. \\
& \left.+\frac{\sum_{j \neq 0, i}\left(T_{j}-T_{0}+\mathrm{d} T_{i}-\mathrm{d} T_{0}\right) h_{j}^{\prime}}{1+A_{i}}\right)
\end{aligned}
$$

and

$$
\mathrm{d} c_{i}-x\left(h_{0}^{\star \star}, c_{0}+\mathrm{d} c_{0}\right)+x\left(h_{0}^{\star \prime}, c_{0}+\mathrm{d} c_{0}\right) \geq 0
$$

where $\tilde{g}_{i}=u^{\prime}\left(c_{i}+\mathrm{d} c_{i}+x\left(h_{0}^{\star \prime}, c_{0}+\mathrm{d} c_{0}\right)\right) / p$, and $h_{j}^{\prime}=h_{j}^{\prime}\left(c_{j}+\mathrm{d} c_{j}+x\left(h_{0}^{\star \prime}, c_{0}+\mathrm{d} c_{0}\right)\right)$ when no argument is otherwise given for the function's derivative. As for $i=0$, it becomes:

$$
\begin{gathered}
\sum_{j>0} h_{j} \tilde{g}_{j} x_{c}+h_{0}^{\star \prime}\left(g_{0}-1\right)+\sum_{j>0}\left(T_{i}+\mathrm{d} T_{i}-T_{0}-\mathrm{d} T_{0}\right) \frac{\mathrm{d} h_{j}}{\mathrm{~d} c_{0}} \leq 0 \\
\text { and } \\
\mathrm{d} c_{0} \geq 0 .
\end{gathered}
$$

Careful readers will observe that this is nearly identical to the optimal tax solution in the presence of social norms, as derived in Subsection 3. To see this more clearly, denote $T_{i}^{\prime} \equiv T_{i}+\mathrm{d} T_{i}$ and $c_{i}^{\prime} \equiv c_{i}+\mathrm{d} c_{i}$. The optimal tax solution can then be written as:

$$
\frac{T_{i}^{\prime}-T_{0}^{\prime}}{c_{i}^{\prime}-c_{0}^{\prime}}=\frac{1-\tilde{g}_{i}}{\xi_{i}}+\frac{x_{h}}{c_{i}^{\prime}-c_{0}^{\prime}}\left(\frac{\sum_{j>0} h_{j} \tilde{g}_{j}}{1+A_{i}}+\frac{\sum_{j \neq 0, i}\left(T_{j}^{\prime}-T_{0}^{\prime}\right) h_{j}^{\prime}}{1+A_{i}}\right)
$$

In contrast, rewriting equation (16) using the same definitions yields (in the case where it binds):

$$
\frac{T_{i}^{\prime}-T_{0}^{\prime}}{c_{i}^{\prime}-c_{0}^{\prime}}=\frac{1-\tilde{g}_{i}}{\xi_{i}}-\frac{\lambda}{p \xi_{i}} h_{i}^{\prime}\left(c_{j}-c_{0}+x\left(h_{0}^{\star \star}, c_{0}\right)\right)+\frac{x_{h}}{c_{i}^{\prime}-c_{0}^{\prime}}\left(\frac{\sum_{j>0} h_{j} \tilde{g}_{j}}{1+A_{i}}+\frac{\sum_{j \neq 0, i}\left(T_{j}^{\prime}-T_{0}^{\prime}\right) h_{j}^{\prime}}{1+A_{i}}\right) .
$$

The term by which the last equation differs from the one immediately above it is given by:

$$
-\frac{\lambda}{p \xi_{i}} h_{i}^{\prime}\left(c_{j}-c_{0}+x\left(h_{0}^{\star \star}, c_{0}\right)\right)<0 .
$$

This term reduces the extent of possible redistribution compared with the initial optimal tax problem. It reflects the constraint that the social planner needs to achieve at least the required initial shift in participation, which must likely pass through an overall decrease in redistribution. The greater is the required shift, the more binding is the constraint and the greater is the multiplier $\lambda>0$ associated with it. Hence, redistribution is then further constrained. The requirement that the shift between equilibria be Pareto-improving also limits redistribution, whenever to solution for 
at least some $i>0$ is given by:

$$
\begin{aligned}
\frac{T_{i}^{\prime}-T_{0}^{\prime}}{c_{i}^{\prime}-c_{0}^{\prime}}< & \frac{1-\tilde{g}_{i}}{\xi_{i}}-\frac{\lambda}{p \xi_{i}} h_{i}^{\prime}\left(c_{j}-c_{0}+x\left(h_{0}^{\star \star}, c_{0}\right)\right) \\
& +\frac{x^{\prime}}{c_{i}^{\prime}-c_{0}^{\prime}}\left(\frac{\sum_{j>0} h_{j} \tilde{g}_{j}}{1+A_{i}}+\frac{\sum_{j \neq 0, i}\left(T_{j}^{\prime}-T_{0}^{\prime}\right) h_{j}^{\prime}}{1+A_{i}}\right)
\end{aligned}
$$

and

$$
\mathrm{d} c_{i}-x\left(h_{0}^{\star \star}, c_{0}+\mathrm{d} c_{0}\right)+x\left(h_{0}^{\star \prime}, c_{0}+\mathrm{d} c_{0}\right)=0 .
$$

That is, when the decrease in $c_{i}$ is just compensated by the increase in the inducement to co-operate that results from the shift in equilibria.

\section{Differences in the requirements for pessimistic selection: outcomes being attributed} to either luck or effort Note that equation (18) may differ depending on whether outcomes are attributed to luck or effort.

In the case where outcomes are attributed to $l u c k, x\left(h_{0}^{\star \star}, c_{0}\right) \geq 0$. This also increases in $c_{0}$, ceteris paribus. How this affects the magnitude of (18), and constrains the possible extent of redistribution (as measured by participation taxes) while undergoing pessimistic selection in turn depends upon the characteristics of $h_{i}^{\prime}(\cdot)$. If $h_{i}^{\prime \prime}<0$ (i.e., the cumulative distribution function of preferences for leisure in class $i, \Gamma_{i}(\cdot)$ is strictly concave at the point where it is evaluated), then a positive $x$, and an increasing one at that, will make (18) smaller in absolute value. This therefore allows, ceteris paribus, for higher participation taxes to prevail when inducing such a shift.

Conversely, if $h_{i}^{\prime \prime}>0$ (meaning that $\Gamma_{i}$ is strictly convex at the point in question), the inclusion of a positive moral benefit $x$ increasing in $c_{0}$ will make (18) larger in absolute value, thereby further reducing participation taxes and tightening the constraint on the social planner trying to induce a shift in participation equilibria.

In contrast, when outcomes are attributed to effort, $x\left(h_{0}^{\star \star}, c_{0}\right)<0, \forall c_{0}, h_{0}>0$. If $h_{i}^{\prime \prime}<0$, the inclusion of $x\left(h_{0}, c_{0}\right)<0$ decreases participation taxes by making 18) more negative (i.e. larger in absolute value) relative to when outcomes are attributed to luck, and the more so the higher are $h_{0}$ and $c_{0}$. It therefore tightens the constraint on redistribution when undergoing pessimistic selection, allowing only lower participation taxes.

On the contrary, if $h_{i}^{\prime \prime}>0$, having $x\left(h_{0}, c_{0}\right)<0$ makes (18) smaller in absolute value, thereby having the opposite effect to the one found when outcomes are attributable to luck: this loosens the constraint on redistribution when inducing a shift in participation, from a low- to a highparticipation equilibrium. 


\section{Discussion and Conclusion}

This paper sought to establish the importance of societal consensus for questions of (optimal) redistribution, with this consensus being induced by social norms that embody views of distributive justice and affect work participation decisions. It first particularly examined the implications of a social norm concerning work participation - included as either an inducement (deterrent) to co-operate through a moral benefit (cost) for participants, or as a moral cost of stigma for non-participants for optimal income taxation and the extent of redistribution, in the case of a naïve social planner abstracting from the risks of a dramatic breakdown in societal cohesion. This breakdown was characterized by a sharp reduction in work participation numbers and the overall transition from a highto a low-participation equilibrium, by way of an initial decrease in participation compounded by the social norm through decreases in the inducements to co-operate. The nature of the initial shock in participation required to trigger a shift in participation equilibria was thereafter characterized. The Pareto-desirability of a shift going from a low- to a high-participation equilibrium was also considered, and a set of conditions guaranteeing the required magnitude and the Pareto-improving nature of the shift were derived. Lastly, it was studied how such a shift may optimally be implemented by a social planner (or party in power) with a certain welfarist objective function, for instance one with a particular aversion to inequality.

It was first found that in the presence of a social norm affecting participants, the optimal scope for redistribution - measured by the participation tax, and as chosen by a social planner in the manner of Saez (2002) (based on the contribution of Diamond, 1980) - is reduced compared with the case where it is absent. This is explained in part by the feedback effects of a decrease in participation, which lower the incitements to sustain societal co-operation, thus increasing the budgetary costs of redistribution. The benefits of greater participation for the welfare of participants, and social welfare overall, also go towards justifying this. The planner therefore seeks to foster participation to a greater extent than in the absence of a social norm.

This result is not as stark when the social norm is included as a cost of stigma for nonparticipants, also reflecting the view that economic outcomes are the result of effort, rather than when it affects participants: provided that the incentive to compensate non-participants for the moral costs incurred is stronger than the negative feedback effects on work participation of doing so, the optimal participation tax is then greater in the presence of a social norm than in its absence. These results importantly hinge on the elasticities of participation being identical between the cases with and without social norms.

When the social norm was such that it exhibited multiple, locally-stable equilibria in participation, it was found that a sufficient increase in the progressivity of the tax system could lead to a shift in participation regimes from a high- to a low-participation equilibrium. Conversely, it generally took a decrease in the progressivity of the income tax so as to trigger the opposite shift, from a low- to a high-participation equilibrium. In between-equilibria welfare comparisons (i.e., abstracting from the transition dynamics), such a shift was found to be Pareto-improving when the social norm is modelled as affecting participants, and when the increase in this benefit between equilibria at 
least compensated those incurring an initial loss in consumption. The shift in the tax system that fits best with a social planner's objective function was thereafter found to further constrain the possible extent of redistribution.

It thus appears that in order to engineer a shift in participation equilibria, from a low- to a high-participation equilibrium, a social planner or party in office that is averse to inequality must somewhat compromise with this objective by decreasing tax progressivity, compared with what it would normally choose if unconstrained. Why would any planner or party ever choose such a course of action, then? Done optimally, this decrease in progressivity can be minimal, especially if the initial required shock to participation is of a small magnitude. Furthermore, at a high-participation equilibrium, the potential for redistribution is thereafter greater, due to a greater tax base and the possibility of increasing progressivity once more.

But engineering such a shift nonetheless poses a serious political economy conundrum. To freely adopt such a policy, the party in power must foresee few electoral costs in doing so and have a low aversion to inequality. On the contrary, a party whose social objective function includes a strong aversion to inequality will need to convince voters (at the very least its party base, if not more) that such a transformation, despite being contrary to its principles and leading to at least some groups losing in the short term, is in everyone's interest the longer run. Claiming that this is possible supposes that the party in power is far-sighted (that is to say, both its leadership and membersat-large see eye-to-eye on this policy's desirability, and the influence of opportunists and careerists is limited so as to allow its implementation), and that the electorate shares this clear view of the future. Even in the presence of such far-seeing agents, such an engineered shift may be compromised by too slow a transition between equilibria leading to impatient voters, instability in government, and possibly contradictory policies. It may even be necessary to elect a party without any particular aversion to inequality so as to engineer such a shift, and revert to electing more inequality-averse parties only when participation is at a high equilibrium once again. This narrative would appear to fit the examples of late-1970s, early-1980s Britain, and especially early-1990s Sweden or mid-1990s Ontario, for instance.

\section{References}

Akerlof, George. 1980. "A Theory of Social Custom, of Which Unemployment May be One Consequence." The Quarterly Journal of Economics 94(4):749-775.

Aronsson, Thomas and Tomas Sjögren. 2010. "Optimal Income Taxation and Social Norms in the Labor Market." Journal of International Taxation and Public Finance 17:67-89.

Barr, Nicholas. 2004. The Economics of the Welfare State (Fourth Edition). Oxford University Press.

Bénabou, Roland and Jean Tirole. 2006. "Belief in a Just World and Redistributive Politics." The Quarterly Journal of Economics 121(2):699-746. 
Cervellati, Matteo, Joan Esteban and Laurence Kranich. 2010. "Work Values, Endogenous Sentiments and Redistribution." Journal of Public Economics 94(9-10):612-627.

Diamond, Peter. 1980. "Income Taxation with Fixed Hours of Work." Journal of Public Economics 13(1):101-110.

Dufwenberg, Martin and Michael Lundholm. 2001. "Social Norms and Moral Hazard." The Economic Journal 111(473):pp. 506-525.

Gordon, James P.F. 1989. "Individual Morality and Reputation Costs as Deterrents to Tax Evasion." European Economic Review 33:797-805.

Lindbeck, Assar. 1995. "Welfare State Disincentives with Endogenous Habits and Norms." The Scandinavian Journal of Economics 97(4):477-494.

Lindbeck, Assar. 1996. Full Employment and the Welfare State. The Frank E. Seidman Distinguished Award in Political Economy P.K. Seidman Foundation. Acceptance paper.

Lindbeck, Assar, Sten Nyberg and Jörgen W. Weibull. 1999. "Social Norms and Economic Incentives in the Welfare State." Quarterly Journal of Economics 114(1):1-35.

Lindbeck, Assar, Sten Nyberg and Jörgen W. Weibull. 2003. "Social Norms and Welfare State Dynamics." Journal of the European Economic Association 1(2/3):533-542.

Meltzer, Allan H. and Scott F. Richard. 1981. "A Rational Theory of the Size of Government." The Journal of Political Economy 89(5):914-927.

Murray, Charles. 1984. Losing Ground: American Social Policy, 1950-1980. Basic Books.

Myles, Gareth D. and Robin A. Naylor. 1996. "A Model of Tax Evasion with Group Conformity and Social Customs." European Journal of Political Economy 12:49-66.

Nozick, Robert. 1974. Anarchy, State, and Utopia. Basic Books.

Rawls, John. 1971. A Theory of Justice. Harvard University Press.

Romer, Thomas. 1975. "Individual welfare, majority voting, and the properties of a linear income tax." Journal of Public Economics 4(2):163 - 185.

Saez, Emmanuel. 2002. "Optimal Income Transfer Programs: Intensive Versus Extensive Labor Supply Responses." Quarterly Journal of Economics 117(3):1039-1073.

Saez, Emmanuel and Stefanie Stantcheva. 2013. Generalized Social Marginal Welfare Weights for Optimal Tax Theory. Technical report UC Berkeley.

Skidelsky, Robert. 1997. Beyond the Welfare State. The Social Market Foundation. 